\title{
BMJ Open Systematic review of clinical outcome reporting in randomised controlled trials of burn care
}

\author{
Amber E Young, ${ }^{1}$ Anna Davies, ${ }^{1}$ Sophie Bland, ${ }^{2}$ Sara Brookes, ${ }^{1,3}$ Jane M Blazeby ${ }^{1}$
}

To cite: Young AE, Davies A, Bland S, et al. Systematic review of clinical outcome reporting in randomised controlled trials of burn care. BMJ Open 2019;9:e025135. doi:10.1136/

bmjopen-2018-025135

- Prepublication history and additional material for this paper are available online. To view these files, please visit the journal online (http://dx.doi. org/10.1136/bmjopen-2018025135).

Received 4 July 2018

Revised 20 November 2018

Accepted 3 December 2018

Check for updates

(C) Author(s) (or their employer(s)) 2019. Re-use permitted under CC BY. Published by BMJ.

${ }^{1}$ Population Health Sciences, Bristol Medical School,

University of Bristol, Bristol, UK

${ }^{2}$ Patient representative, Bristol, Avon, UK

${ }^{3}$ Cancer Research UK Clinical Trials Unit (CRCTU), Institute of Cancer and Genomic Sciences, University of Birmingham, Birmingham, UK

Correspondence to

Dr Amber E Young;

amber.young1@nhs.net

\begin{abstract}
Introduction Systematic reviews collate trial data to provide evidence to support clinical decision-making. For effective synthesis, there must be consistency in outcome reporting. There is no agreed set of outcomes for reporting the effect of burn care interventions. Issues with outcome reporting have been identified, although not systematically investigated. This study gathers empirical evidence on any variation in outcome reporting and assesses the need for a core outcome set for burn care research.
\end{abstract}

Methods Electronic searches of four search engines were undertaken from January 2012 to December 2016 for randomised controlled trials (RCTs), using medical subject headings and free text terms including 'burn', 'scald' 'thermal injury' and 'RCT'. Two authors independently screened papers, extracted outcomes verbatim and recorded the timing of outcome measurement. Duplicate outcomes (exact wording \pm different spelling), similar outcomes (albumin in blood, serum albumin) and identical outcomes measured at different times were removed. Variation in outcome reporting was determined by assessing the number of unique outcomes reported across all included trials. Outcomes were classified into domains. Bias was reduced using five researchers and a patient working independently and together.

Results 147 trials were included, of which 127 (86.4\%) were RCTs, $13(8.8 \%)$ pilot studies and 7 (4.8\%) RCT protocols. 1494 verbatim clinical outcomes were reported; 955 were unique. $76.8 \%$ of outcomes were measured within 6 months of injury. Commonly reported outcomes were defined differently. Numbers of unique outcomes per trial varied from one to 37 (median 9; IQR 5,13). No single outcome was reported across all studies demonstrating inconsistency of reporting. Outcomes were classified into 54 domains. Numbers of outcomes per domain ranged from 1 to 166 (median 11; IQR 3,24).

Conclusions This review has demonstrated heterogeneity in outcome reporting in burn care research which will hinder amalgamation of study data. We recommend the development of a Core Outcome Set.

PROSPERO registration number CRD42017060908.

\section{INTRODUCTION}

Each year an estimated 2-300000 people die from burn injuries globally. ${ }^{1}$ Millions more suffer from burn-related disabilities and disfigurements. $^{2}$ These injuries have functional, psychological, social and economic

\section{Strengths and limitations of this study}

This review is a comprehensive and systematic search for all clinical outcomes reported in randomised controlled trials of burn care between and including 2012 and 2016.

- There is a detailed analysis of all reported outcomes and timing of outcome assessment.

- A multidisciplinary team including a patient were involved in the study.

- Quality assessment of studies was not undertaken as the purpose of the review was to extract clinical outcomes alone and not to assess the effect of an intervention.

effects on survivors and their families. There are multiple strategies for managing burn wounds and the associated impact on patient physiology, with new care pathways and technology being introduced on a regular basis. ${ }^{3-5}$ The choice of treatment should be made using up-to-date, high quality scientific evidence. ${ }^{67}$ Systematic reviews of randomised controlled trials (RCT) are regarded as the highest quality evidence. ${ }^{8-10}$ Despite increasing numbers of published RCTs in burn care, systematic reviews have not provided evidence to support many commonly used interventions or management strategies. ${ }^{11-13}$

A well-designed RCT requires that outcomes are prespecified. Evidence synthesis requires that these outcomes are consistent across RCTs in the same healthcare area. ${ }^{14}$ In the context of clinical trials, Williamson et al in the Core Outcome Measures in Effectiveness Trials (COMET) handbook, define an outcome as 'a measurement or observation used to capture and assess the effect of treatment such as assessment of side effects (risk) or effectiveness (benefits) ${ }^{15}$ Chan adds a temporal element: 'a variable measured at a specific time point to assess the efficacy or harm of an intervention'. ${ }^{16}$ If RCTs report outcomes that cannot be collated due to differences in choice, definition or timepoint 
of assessment, evidence synthesis will not be effective or efficient. There is no agreed minimum set of outcomes important to patients and professionals for reporting in burn care trials and problems with outcome reporting in burn care research have previously been suggested. ${ }^{17-19}$

Prespecifying outcomes requires research to determine and agree the most important outcomes for a clinical condition. If this is not undertaken, the outcomes reported may not reflect patients' or other stakeholders' needs, outcomes will vary between studies (outcome reporting heterogeneity), and it will be difficult to determine if authors have reported all the outcomes they measured (outcome reporting bias). ${ }^{20}{ }^{21}$ Choosing the most important outcomes to measure in burn care is complex, as patients are a heterogeneous population, with variations in age, mechanism of injury, depth, site and size of burn. ${ }^{22}{ }^{23}$ The time frame at which outcomes are measured may also determine the types of outcomes assessed. Outcomes reported in clinical trials during the acute treatment phase include healing time, skin-graft loss, infection rates and National Health Service costs. ${ }^{24-27}$ Longer-term reported outcomes relate to functional, cosmetic and psychological issues. ${ }^{28}$

To date, there has been no formal investigation into outcome reporting in trials of burn care. The purpose of this study is to examine clinical outcome reporting in burn care research, to consider the types, definitions and timing of outcomes measured and to consider the need for a Core Outcome Set (COS) in this field.

\section{METHODS}

This review is focused on clinical, observer-reported outcomes in RCTs assessing the impact of interventions in burn care. It adhered to a prespecified protocol and the Preferred Reporting Items for Systematic Reviews and Meta-Analyses (PRISMA) statement. ${ }^{29}$

\section{Study eligibility}

Studies were included if they met the following:

Types of studies: We included full text RCTs along with RCT protocols and pilot studies. The study design was limited to RCTs, as any final COS will be used for RCT reporting. ${ }^{29}$ We excluded protocols and pilot studies if the full RCT had been published within the selected time period. We also excluded conference proceedings and abstracts, non-English language publications and studies not involving human subjects.

Types of participants: We included studies recording outcomes from patients of any age with a cutaneous burn of any type or size, determined by either clinician evaluation or objective assessment, or both, which required treatment in any healthcare facility. Studies where the population consisted of patients with combined thermal and mechanical injuries were only included if it was possible to separate out the burn care outcomes. Trials studying patients with pure carbon monoxide poisoning, chemical ocular or caustic oesophageal burns were excluded, as the former does not involve a burn and the latter have different aetiology and management to cutaneous burns.

Type of interventions: Any surgical or non-surgical burn care intervention with any appropriate comparator.

Types of outcomes: Defined as the exact terms used in a published trial abstract, methods or results including tables and figures for any observer-reported clinical endpoint. These included physiological, metabolic or adverse or mortality events measured by researchers and relevant to patients' recovery and long-term well-being after burn care. ${ }^{30}$ Trials assessing quality of life were only included if the data were observer-reported.

\section{Identification of studies}

Electronic searches of Ovid MEDLINE, Ovid EMBASE, Web of Science and The Cochrane Library were searched from 1 January 2012 to 31 December 2016 for RCTs related to burn care using medical subject heading and free text terms including 'burn', 'scald' 'thermal injury' and 'RCT'. This period was chosen so that the outcomes extracted, reflected use in trials relating to modern burn care. Limiting the review to 5 years allowed us to balance workload against the likelihood of selecting enough trials fulfilling inclusion criteria to demonstrate whether heterogeneity of outcome reporting was present in burn care research. The thesaurus vocabulary of each database was used to adapt the search terms. The search strategy for Ovid MEDLINE is included in a previous publication and in online supplementary appendix A. ${ }^{29}$

\section{Study selection process}

Prior to both abstract and full-text screening, all review authors underwent training to ensure a comparable understanding of the purpose of the review and the eligibility criteria. The reference management software EndNote V.6 (Clarivate Analytics, Boston; available at http://endnote.com/) was used to compile all titles derived from the initial searches, with duplicates removed for the review authors to screen titles and abstracts against the eligibility criteria. Screening of titles and abstracts was completed independently, then in duplicate by two authors (AY, $\mathrm{AD}$ ) with experience in systematic review methodology. All screening disagreements were discussed, with any outstanding disagreements resolved by an independent reviewer (JB). Any studies appearing to meet the inclusion criteria based on the abstract were retrieved as full-text articles. Two reviewers then read the full-text articles in their entirety to assess for eligibility, with decisions on inclusion and exclusion recorded (figure 1 for flow diagram). Reasons for exclusion were ordered hierarchically (box 1) and applied to each full text. The highest reason for exclusion met by a paper was recorded as its reason for exclusion. Any disagreements were discussed with another author (JB). 

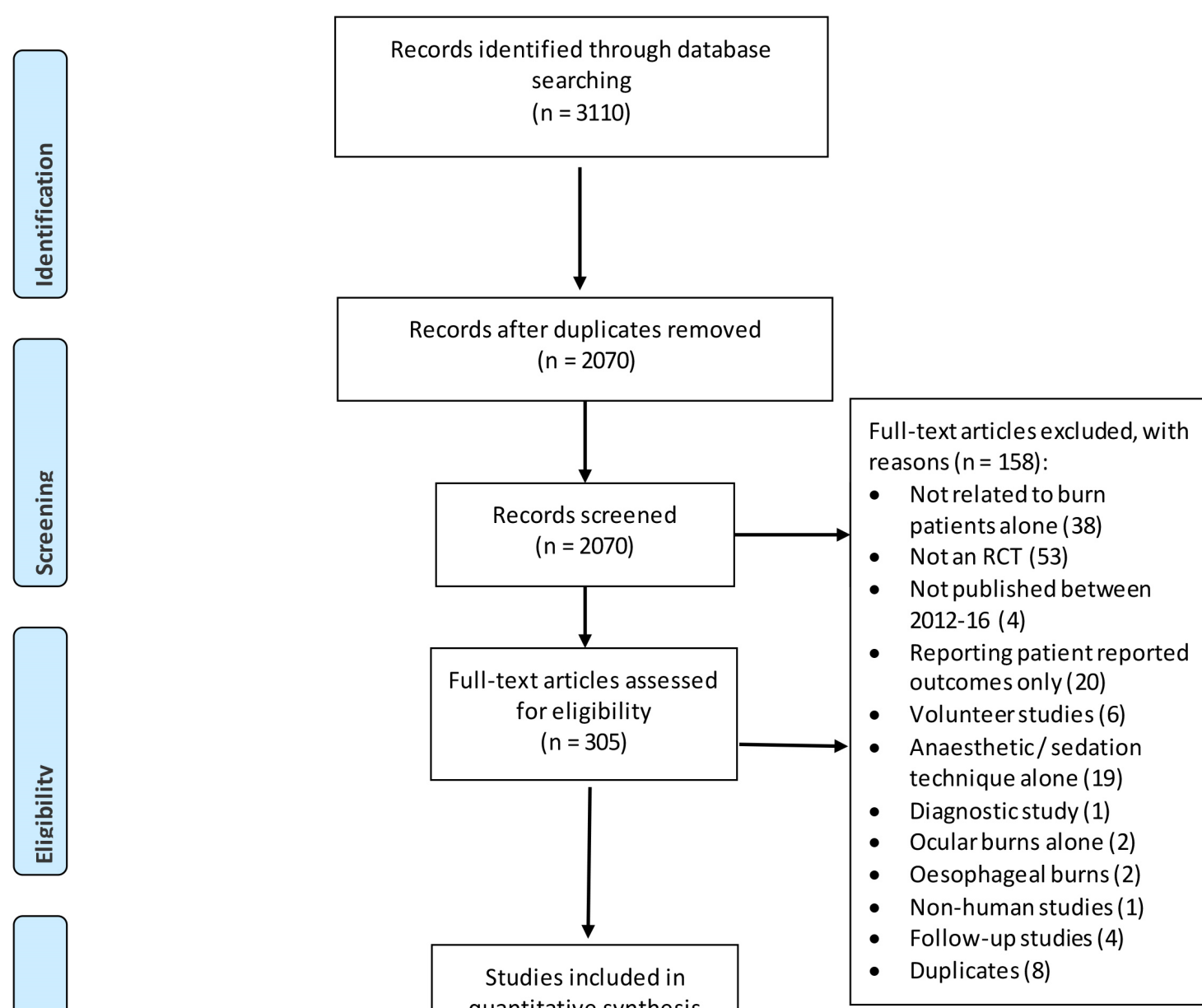

quantitative synthesis ( $n=147)$

Figure 1 Preferred Reporting Items for Systematic Reviews and Meta-Analyses flow diagram. PRO, patient reported outcome; $\mathrm{RCT}$, randomised controlled trial.

\section{Quality assessment}

The aim of this study was to comprehensively document any variation in clinical outcomes selected, defined, measured and reported in burn care RCTs and not to synthesise data about the effect of interventions. Inclusion of all trials was necessary to demonstrate if a variation in outcome reporting was present across trials, regardless of quality of methodology of the trial. We therefore decided not to undertake a quality assessment of studies because it was not relevant to the data being recorded in this review; simply the nature and description of the unique outcomes reported in each study.

\section{Data extraction}

Data were extracted into a standardised data extraction sheet (Microsoft Excel). This included study author, country or countries recruiting (categorised into the United Nations six regions ${ }^{31}$ ), publication year, number of sites and number of participants recruited per trial, design (full RCT, pilot, protocol) and intervention tested.
For protocols, the planned participant inclusion criteria and sample size were extracted.

No distinction was made between primary or secondary outcomes, although this was noted and is part of a separate project. All outcomes were extracted verbatim, with $20 \%$ of the extracted data verified by a second reviewer. True duplicates, spelled and worded the same, were deleted. As a second process, two reviewers (a clinician and researcher) discussed all verbatim outcomes to assess duplicates in meaning but spelled or worded in a slightly different manner; such as length of time in hospital and number of days in hospital, platelet level and levels, and serum interleukin (IL) 10 and IL-10 in blood. These were named as one outcome with wording chosen by the reviewers and the others deleted as duplicates. The remaining outcomes were therefore all different in meaning. Any discrepancies were discussed with a senior researcher (JB). The number of outcomes per trial and the variation of outcomes between trials was recorded. 


\section{Box 1 Hierarchy of exclusion}

1. Duplicate.

2. Not published between 1 January 2012 and 31 December 2016.

3. Not written in English.

4. Not relating to burns or burn care alone.

5. Population is non-human subjects (eg, animal studies, modelling).

6. Abstract with no full text given.

7. Study is not a randomised controlled trial testing an intervention on burn care.

8. Laboratory based, not carried out in clinical setting, for example, exudate or blood samples from humans tested within laboratory.

9. Systematic review paper, commentary paper.

10. Reports only patient-reported outcomes.

11. Volunteer study.

12. Oesophageal burns.

13. Ocular burns.

14. Anaesthetic/sedation technique.

15. Diagnostic test trial.

16. Unavailable anywhere.

17. Follow-up studies.

The time after injury that outcomes were measured were noted separately in order to (a) assess the heterogeneity in outcome measurement timing and (b) to understand at what stage after injury the effects of the intervention were being assessed. If a single outcome was assessed at different timepoints, all assessment timings were recorded. Data extraction for the timing of outcome reporting from $10 \%$ of trials was undertaken independently by another researcher. Timings of outcome assessment were categorised into time periods; $<1$ month, $>1$ month and $\leq 3$ months, $>3$ months and $\leq 6$ months after injury, $>6$ months and $\leq 1$ year and $>1$ year and $\leq 3$ years, and $>3$ years. We reported two other outcome time periods; those assessed during acute hospitalisation and during burn wound healing, as these were commonly reported in the literature with no proscribed timepoint. However, it was clear from the reported length of stay and healing data, that all these outcomes were assessed within 6 months of injury. The frequency of outcomes reported within each time period was recorded.

The data were tabulated so that each study was listed with study and population details along with outcomes measured. Outcomes were extracted from this spreadsheet into another, with duplicates removed as described above. Outcomes measuring the same healthcare issue but at different timepoints were noted as one outcome for the final set. These final unique outcomes were then grouped into domains.

\section{Classification of outcomes into domains}

Outcome domains are groups of similar outcomes. This organisation is necessary, as maintaining a large set of outcomes when a significant number are similar, would make any future classification of the outcomes in terms of importance, extremely challenging.
Outcomes were classified into domains in a threestage iterative approach. In stage 1, four researchers (a clinically trained burn care researcher, a burn research associate and two senior research nurses experienced in burn care) independently reviewed the list of outcomes and attributed a potential domain to each one using their own terms. In stage 2, the researchers met to review the domains and agreed (1) appropriate groupings of outcomes into domains and (2) an appropriate name for each domain. Rules for attribution of outcomes to domains were recorded in a coding log to ensure consistency. In stage 3, a patient representative reviewed the outcomes and their attributed domains to check for clarity of domain name, and that the outcomes under each domain were appropriately attributed. A final meeting with an experienced outcome researcher was held to finalise outcomes and domains. The use of a published classification system was not undertaken as none appeared to allow the flexibility or fit to the types of outcomes reported in burn care trials. ${ }^{32} 33$

The results described below indicate the characteristics of the reported studies and provide detail on heterogeneity of outcome reporting between studies, outcome definitions, timepoints and outcome domains.

\section{Patient involvement}

The need for a burn care COS project was conceived following discussions regarding clinical healthcare Key Performance Indicators with professionals and patients. The patients were vocal about outcomes important to them which they felt were overlooked by professionals, such as pain. The systematic review was discussed at regular project steering group meetings attended by three patients with burns and one parent of a child with burns. A patient with burns is a coauthor and was involved with writing and editing of this article as well as with the naming of the outcome domains. Dissemination will be to the lay representatives of the steering group and will inform the Core Outcome Set study in which patients are actively involved.

\section{RESULTS}

\section{Included studies and study protocols}

The initial search strategy identified 3110 studies. Following de-duplication, a total of 2070 studies remained. Independent scrutiny of the titles and abstracts identified 306 potentially relevant articles for full text review. Of these, 158 studies did not meet our inclusion criteria and were excluded (PRISMA flow diagram; figure 1). Therefore, a total of 147 studies formed the basis of this study. ${ }^{2434-178}$

\section{Studies}

Of the 147 studies (table 1), 86.4\% (127) were reports of full RCTs, $8.8 \%$ (13) were pilot studies and $4.8 \%$ (7) were study protocols. The number of studies published increased between 2012 and 2016, with 26 RCTs published in 2012 and 40 in 2016 (table 2). 
Table 1 Included randomised controlled trials

\section{Trial title}

Year of

1. Comparison of silver nylon wound dressing and silver sulfadiazine in partial burn wound therapy. $^{34}$

2. Healing of burn wounds by topical treatment: A randomized controlled comparison between silver sulfadiazine and nano-crystalline silver. ${ }^{35}$

4. An analysis of deep vein thrombosis in burn patients (part II): A randomized and controlled Ahuja

study of thrombo-prophylaxis with low molecular weight heparin. ${ }^{37}$

2016

5. A four arm, double blind, randomized and placebo-controlled study of pregabalin in the Ahuja management of post-burn pruritus. ${ }^{38}$

6. Propranolol attenuates haemorrhage and accelerates wound healing in severely burned Ali adults. $^{39}$

7. Aerobic exercise training in modulation of aerobic physical fitness and balance of burned Ali patients. ${ }^{40}$

8. Silk sericin ameliorates wound healing and its clinical efficacy in burn wounds. ${ }^{41}$

Aramwit

9. A Randomized Controlled Trial Comparing Endoscopic-Assisted Versus Open Neck Tissue As'adi Expander Placement in Reconstruction of Post-Burn Facial Scar Deformities. ${ }^{42}$

10. A prospective, randomised study of a novel transforming methacrylate dressing compared with a silver-containing sodium carboxymethylcellulose dressing on partialthickness skin graft donor sites in burn patients. ${ }^{43}$

11. Multimodal quantitative analysis of early pulsed-dye laser treatment of scars at a pediatric burn hospital. ${ }^{44}$

12. Early fluid resuscitation with hydroxyethyl starch 130/0.4 (6\%) in severe burn injury: a randomized, controlled, double-blind clinical trial. ${ }^{45}$

Assadian

13. A prospective randomized trial comparing silver sulfadiazine cream with a water-soluble Black poly-antimicrobial gel in partial-thickness burn wounds. ${ }^{46}$

14. Clinical effectiveness of dermal substitution in burns by topical negative pressure: a multicenter randomized controlled trial. ${ }^{47}$

Bailey

Bechir

15. Effect of subcutaneous epinephrine/saline/local anesthetic versus saline-only injection on Blome Eberwein split-thickness skin graft donor site perfusion, healing, and pain. ${ }^{48}$

16. A randomized controlled study of silver-based burns dressing in a pediatric emergency Brown department. ${ }^{49}$

17. Cost-Effectiveness of a Nonpharmacological Intervention in Pediatric Burn Care. ${ }^{50}$ Brown

18. Play and heal: randomized controlled trial of DittoTM intervention efficacy on improving Brown re-epithelialization in pediatric burns. ${ }^{51}$

2015

19. The implementation and evaluation of therapeutic touch in burn patients: an instructive Busch experience of conducting a scientific study within a non-academic nursing setting.

20. Prophylactic sequential bronchoscopy after inhalation injury: results from a 3 year prospective randomized trial. ${ }^{52}$

Carr

21. Burns injury in children: is antibiotic prophylaxis recommended? ${ }^{53}$

Chahed

2013

22. A randomized controlled trial to compare the effects of liquid versus powdered

Chen recombinant human growth hormone in treating patients with severe burns. ${ }^{54}$

Chen

23. The Effect of Continuous Sedation Therapy on Immunomodulation, Plasma Levels of Chen Antioxidants, and Indicators of Tissue Repair in Post-Burn Sepsis Patients. ${ }^{55}$

24. Application of acellular dermal xenografts in full-thickness skin burns. ${ }^{56}$

Chen

25. Effectiveness of medical hypnosis for pain reduction and faster wound healing in

pediatric acute burn injury: study protocol for a randomized controlled trial. ${ }^{57}$

Chen

2013

Chester

26. Safety of recombinant human granulocyte-macrophage colony-stimulating factor in healing paediatric severe burns. ${ }^{58}$

Chi

2016

27. Comparison of three cooling methods for burn patients: A randomized clinical trial. ${ }^{59}$

Cho

2015

2016 
Table 1 Continued

\section{Trial title}

First author

Year of

28. The effect of burn rehabilitation massage therapy on hypertrophic scar after burn: a randomized controlled trial. ${ }^{60}$

Cho publication

29. Effect of extracorporeal shock wave therapy on scar pain in burn patients: A prospective, Cho randomized, single-blind, placebo-controlled study. ${ }^{61}$

2014

30. Characterization of early thermal burns and the effects of hyperbaric oxygen treatment: a Chong pilot study. ${ }^{62}$

31. Effects of different duration exercise programs in children with severe burns. ${ }^{63}$

32. The effect of healing touch on sleep patterns of pediatric burn patients. ${ }^{64}$

2013

33. Effect of $\mathrm{N}$-acetylcysteine treatment on oxidative stress and inflammation after severe burn. ${ }^{65}$

34. The effects of intravenous glutamine supplementation in severely burned, multiple traumatized patients. ${ }^{66}$

$\begin{array}{ll}\text { Clayton } & 2016 \\ \text { Cone } & 2014 \\ \text { Csontos } & 2012\end{array}$

Cucerean-Badica

35. A comparison between occlusive and exposure dressing in the management of burn Dallal wound.

36. Evaluation of the 'Early' Use of Albumin in Children with Extensive Burns: A Randomized Dittrich

Controlled Trial.

2016

37. Interim pressure garment therapy $(4-6 \mathrm{mmHg})$ and its effect on donor site healing in burn Donovan patients: study protocol for a randomised controlled trial. ${ }^{67}$

38. Effect of whole body vibration on leg muscle strength after healed burns: a randomized Ebid controlled trial. ${ }^{68}$

39. Effect of isokinetic training on muscle strength, size and gait after healed pediatric burn: Ebid a randomized controlled study. ${ }^{69}$

40. Effect of 12 week isokinetic training on muscle strength in adult with healed thermal burn. ${ }^{70}$

Ebid

41. Effects of whole-body vibration exercise on bone mineral content and density in thermally injured children. ${ }^{71}$

Edionwe

42. Efficacy of platelet rich plasma application in comparison to conventional dressing therapy in partial thickness burn wound. ${ }^{72}$

2016

Ehmer al Ibran

43. Effect of probiotic administration in the therapy of pediatric thermal burn. ${ }^{73}$

44. Heparin/ $\mathrm{N}$-acetylcysteine: an adjuvant in the management of burn inhalation injury: a study of different doses. ${ }^{74}$

45. The effect of levamisole on mortality rate among patients with severe burn injuries.

46. Impact of stress-induced diabetes on outcomes in severely burned children. ${ }^{76}$

47. Outcome of Burns Treated With Autologous Cultured Proliferating Epidermal Cells: A Prospective Randomized Multi-center Intra-patient Comparative Trial. ${ }^{77}$

2014

48. Randomized controlled trial of three burns dressings for partial thickness burns in children. ${ }^{78}$

El-ghazely 2016

Elsharnouby

49. Topical petrolatum gel alone versus topical silver sulfadiazine with standard gauze dressings for the treatment of superficial partial thickness burns in adults: a randomized controlled trial. ${ }^{79}$

50. HEPBURN - investigating the efficacy and safety of nebulized heparin versus placebo in Glas burn patients with inhalation trauma: study protocol for a multi-center randomized controlled trial. $^{80}$

51. A multi-center study on the regenerative effects of erythropoietin in burn and scalding injuries: study protocol for a randomized controlled trial. ${ }^{82}$

52. Early rehabilitative exercise training in the recovery from pediatric burn. ${ }^{83}$

Gunter

2013

Finnerty

2014

Gardien

Gee Kee

53. Quality of pediatric second-degree burn wound scars following the application of basic Hayashida fibroblast growth factor: results of a randomized, controlled pilot study. ${ }^{84}$

54. Long-term propranolol use in severely burned pediatric patients: a randomized controlled Herndon 2012 study. ${ }^{85}$ 
Table 1 Continued

\section{Trial title}

55. Reversal of growth arrest with the combined administration of oxandrolone and propranolol in severely burned children. ${ }^{86}$

56. Cost-Effectiveness of Laser Doppler Imaging in Burn Care in The Netherlands: A Randomized Controlled Trial. ${ }^{87}$

57. Effect of music intervention on burn patients' pain and anxiety during dressing changes. $^{88}$

58. Low dose of glucocorticoid decreases the incidence of complications in severely burned Huang patients by attenuating systemic inflammation. ${ }^{89}$

Hop

Hsu
Year of publication

Herndon

2016

2016 2016

2015

59. An assessment of early Child Life Therapy pain and anxiety management: A prospective Hyland randomised controlled trial. ${ }^{90}$

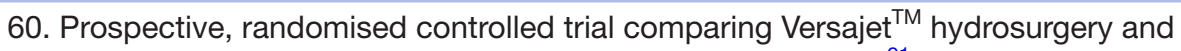
conventional debridement of partial thickness paediatric burns. ${ }^{91}$

Hyland

61. Construction of skin graft seams in burn patients: A prospective randomized doubleblinded study. $^{92}$

Isaac

62. Multi-axis shoulder abduction splint in acute burn rehabilitation: a randomized controlled Jang pilot trial. $^{93}$

63. Glucose control in severely burned patients using metformin: An interim safety and efficacy analysis of a phase II randomized controlled trial. ${ }^{94}$

64. The effect of ketoconazole on post-burn inflammation, hypermetabolism and clinical outcomes. $^{95}$

65. The Effect of Distraction Technique on the Pain of Dressing Change among 3-6 Year-old Kaheni Children. $^{96}$

66. Prospective randomize-controlled comparison between silicone plus herbal extract gel versus Aloe Vera gel for burn scar prophylaxis. ${ }^{97}$

2015

Jeschke

Jeschke

2012

67. Effects of Enteral Glutamine Supplementation on Reduction of Infection in Adult Patients Kibor with Severe Burns. ${ }^{98}$

68. Effects of sustained release growth hormone treatment during the rehabilitation of adult Kim

severe burn survivors. ${ }^{99}$

2016

Keorochana

2014

69. Virtual reality for acute pain reduction in adolescents undergoing burn wound care: a prospective randomized controlled trial. ${ }^{100}$

70. The effects of splinting on shoulder function in adult burns. ${ }^{101}$

Kipping

2012

Kolmus

2012

71. Prospective study on burns treated with Integra, a cellulose sponge and split thickness Lagus skin graft: comparative clinical and histological study--randomized controlled trial. ${ }^{102}$

72. Evaluation of an oxygen-diffusion dressing for accelerated healing of donor-site wounds. 103

73. Anti-inflammatory effect of taurine in burned patients. ${ }^{104}$

74. A randomized controlled pilot study comparing aqueous cream with a beeswax and herbal oil cream in the provision of relief from postburn pruritus. ${ }^{105}$

75. Human acellular dermal matrix allograft: A randomized, controlled human trial for the long-term evaluation of patients with extensive burns. ${ }^{106}$

76. Selective digestive decontamination attenuates organ dysfunction in critically ill burn patients. $^{107}$

77. Results of a prospective randomized controlled trial of early ambulation for patients with Lorello lower extremity autografts. ${ }^{108}$

78. Moist occlusive dressing (Aquacel( $\hat{A}) A g)$ versus moist open dressing (MEBO $(\hat{A}))$ in the management of partial-thickness facial burns: a comparative study in Ain Shams University. ${ }^{109}$

79. Enhancement of burn wounds healing by platelet dressing. ${ }^{110}$

80. Effect of immune-enhancing diets on the outcomes of patients after major burns. ${ }^{111}$

Maghsoud

2012

2013

2014

Continued 
Table 1 Continued

Trial title

Year of

81. Silver-coated nylon dressing plus active DC microcurrent for healing of autogenous skin Malin donor sites. ${ }^{112}$

2013

82. The application of platelet-rich plasma in the treatment of deep dermal burns: A Marck

randomized, double-blind, intra-patient-controlled study. ${ }^{113}$

2016

83. Clinical safety and efficacy of probiotic administration following burn injury. ${ }^{114}$ Mayes

2015

84. Three donor site dressings in pediatric split-thickness skin grafts: study protocol for a McBride randomised controlled trial. ${ }^{115}$

2015

85. Evaluation of who oral rehydration solution (ORS) and salt tablets in resuscitating adult Moghazy patients with burns covering more than $15 \%$ of total body surface area (TBSA). ${ }^{116}$

2016

86. Efficacy and adverse events of early high-frequency oscillatory ventilation in adult burn Mohamed patients with acute respiratory distress syndrome. ${ }^{117}$

87. Effect of amniotic membrane on graft take in extremity burns. ${ }^{118}$

88. Comparison of the application of allogeneic fibroblast and autologous mesh grafting with Moravvej

conventional method in the treatment of third-degree burns. ${ }^{119}$

2016

89. Effect of low-intensity laser on the neuropathic common peroneal nerve post burn. ${ }^{120}$ Mowafy 2016

90. Clinical Efficacy Test of Polyester Containing Herbal Extract Dressings in Burn Wound Muangman

Healing. ${ }^{121}$

2016

91. Effect of oral olive oil on healing of $10 \%-20 \%$ total body surface area burn wounds in Najmi hospitalized patients. ${ }^{123}$

92. Double-blind, randomized, pilot study assessing the resolution of postburn pruritus. ${ }^{124}$

93. Comparing outcomes of sheet grafting with 1:1 mesh grafting in patients with thermal burns: a randomized trial. ${ }^{125}$

94. Comparison of hydrogel produced by radiation as applied at the research center (Yazd branch) with maxgel and routine dressing for second-degree burn repair in Yazd burn hospital. ${ }^{126}$

95. Effectiveness of cerium nitrate-silver sulfadiazine in the treatment of facial burns: a multi- Oen center, randomized, controlled trial. ${ }^{127}$

2012

96. Influences of purposeful activity versus rote exercise on improving pain and hand Omar function in pediatric burn. ${ }^{128}$

Nedelec

2015

97. Botulinum toxin and burn induces contracture. ${ }^{130}$

2012

98. Results of a pilot multi-center genotype-based randomized placebo-controlled trial of

propranolol to reduce pain after major thermal burn injury. ${ }^{129}$

Omranifard

2016

Orrey

2012

99. A proper enteral nutrition support improves sequential organ failure score and decreases Ostradrahimi

length of stay in hospital in burned patients. ${ }^{131}$

100. Topical silver sulfadiazine vs collagenase ointment for the treatment of partial thickness Ostlie

burns in children: a prospective randomized trial. ${ }^{132}$

101. Prospective randomized phase II Trial of accelerated re-epithelialization of superficial second-degree burn wounds using extracorporeal shock wave therapy. ${ }^{133}$

Ottomann

102. A randomized and controlled multi-center prospective study of the Chinese medicinal compound Fufang Xuelian Burn Ointment for the treatment of superficial and deep seconddegree burn wounds. ${ }^{134}$

Ouyang

2012

103. Prospective comparison of packed red blood cell-to-fresh frozen plasma transfusion

ratio of $4: 1$ vs $1: 1$ during acute massive burn excision. ${ }^{135}$

2014

104. A herbal cream consisting of Aloe Vera, Lavandulastoechas, and Pelargonium roseum as an alternative for silver sulfadiazine in burn management. ${ }^{136}$

Palmieri

2012

Panahi

105. Interactive gaming consoles reduced pain during acute minor burn rehabilitation: A randomized, pilot trial. ${ }^{137}$

Parker

106. A Pilot Prospective Randomized Control Trial Comparing Exercises Using Videogame

Therapy to Standard Physical Therapy: 6 Months Follow-Up. ${ }^{138}$

2016

Parry

2015

Continued 
Table 1 Continued

\section{Trial title}

First author

Year of

107. An open, prospective, randomized pilot investigation evaluating pain with the use of a Patton

soft silicone wound contact layer vs bridal veil and staples on split thickness skin grafts as a

primary dressing. ${ }^{139}$

2013

108. Effects of community-based exercise in children with severe burns: A randomized trial. ${ }^{140}$

109. Effects of propranolol and exercise training in children with severe burns. ${ }^{14}$

110. Five-year outcomes after oxandrolone administration in severely burned children: a randomized clinical trial of safety and efficacy. ${ }^{142}$

111. Clinical effectiveness, quality of life and cost-effectiveness of Flaminal versus Flamazine Rashaan in the treatment of partial thickness burns: study protocol for a randomized controlled trial. ${ }^{144}$

112. Five-Year Outcomes after Long-Term Oxandrolone Administration in Severely Burned Children: A Randomized Clinical Trial. ${ }^{145}$

Reeves

Pena

Porro

Porro

2013

113. A novel rapid and selective enzymatic debridement agent for burn wound management: Rosenburg a multi-center RCT. ${ }^{146}$

114. Effects of cholecalciferol supplementation and optimized calcium intakes on vitamin D status, muscle strength and bone health: a 1 year pilot randomized controlled trial in adults

Rousseau

2012 with severe burns. ${ }^{147}$

115. Evaluation of Amniotic Membrane Effectiveness in Skin Graft Donor Site Dressing in Burn Patients. ${ }^{148}$

116. A feasibility study assessing cortical plasticity in chronic neuropathic pain following burn injury. ${ }^{143}$

117. Perioperative treatment algorithm for bleeding burn patients reduces allogeneic blood product requirements. ${ }^{149}$

118. A prospective clinical trial comparing Biobrane, Dressilk, and PolyMem dressings on partial-thickness skin graft donor sites. ${ }^{150}$

119. Effectiveness of Aloe Vera gel compared with $1 \%$ silver sulphadiazine cream as burn wound dressing in second degree burns. ${ }^{151}$

120. The comparison between modified kligman formulation versus kligman formulation and Siadat intense pulsed light in the treatment of the post-burn hyperpigmentation. ${ }^{152}$

121. A comparative study of spray keratinocytes and autologous meshed split-thickness skin Sood graft in the treatment of acute burn injuries. ${ }^{154}$

122. Long-Term Administration of Oxandrolone Improves Lung Function in Pediatric Burned Sousse Patients. ${ }^{155}$

123. An open, parallel, randomized, comparative, multicenter investigation evaluating the efficacy and tolerability of Mepilex Ag versus silver sulfadiazine in the treatment of deep partial-thickness burn injuries. ${ }^{156}$

124. Non-ablative fractional laser provides long-term improvement of mature burn scars - A Taudorf randomized controlled trial with histological assessment. ${ }^{157}$

Salehi

Santos Portilla

Schaden

Schulz

Shahzad

125. Fluid therapy lidco controlled trial - Optimization of volume resuscitation of extensively Tokarik burned patients through noninvasive continuous real-time hemodynamic monitoring LiDCO. ${ }^{158}$

126. Burn donor site dressing using melolin and flexigrid versus conventional dressing. ${ }^{159}$

127. Laser Doppler imaging as a tool in the burn wound treatment protocol. ${ }^{160}$

128. Low-dose hydrocortisone reduces norepinephrine duration in severe burn patients: a randomized clinical trial. ${ }^{161}$

Tang

129. A Comparative Study of Paediatric Thermal Burns Treated with Topical Heparin and Without Heparin. ${ }^{162}$

130. Aquacel() Ag dressing versus ActicoatTM dressing in partial thickness burns: a prospective, randomized, controlled study in 100 patients. Part 1: burn wound healing. ${ }^{24}$ 131. Skin stretching for primary closure of acute burn wounds. ${ }^{163}$
2015

Vejdan 2015

Venclauskiene 2014

Venet

2015

Venkatachalapathy 2014

Verbelen

2014

2014

Continued 
Table 1 Continued

\section{Trial title}

Year of

132. Xbox KinectTM based rehabilitation as a feasible adjunct for minor upper limb burns

rehabilitation: A pilot $\mathrm{RCT}^{164}$ publication

2016

133. Local application of low-dose insulin in improving wound healing after deep burn surgery. ${ }^{165}$

First author

Voon

134. Gabapentin is ineffective as an analgesic adjunct in the immediate postburn period. ${ }^{166}$

Wang

2016

135. A prospective randomised clinical pilot study to compare the effectiveness of Biobrane Wood

(R) synthetic wound dressing, with or without autologous cell suspension, to the local

standard treatment regimen in paediatric scald injuries. ${ }^{167}$

2012

136. Effective symptomatic treatment for severe and intractable pruritus associated with

severe burn-induced hypertrophic scars: A prospective, multicenter, controlled trial. ${ }^{168}$

$\mathrm{Wu}$

137. Propranolol reduces cardiac index but does not adversely affect peripheral perfusion in Wurzer severely burned children. ${ }^{169}$

2016

138. A new method of microskin autografting with a Vaseline-based moisture dressing on Xiao granulation tissue. ${ }^{170}$

2014

139. Recombinant human granulocyte-macrophage colony-stimulating factor hydrogel promotes healing of deep partial thickness burn wounds. ${ }^{171}$

Yan

140. A comparative study of the dressings silver sulfadiazine and Aquacel Ag in the management of superficial partial-thickness burns. ${ }^{172}$

Yarboro

141. A clinical trial designed to evaluate the safety and effectiveness of a thermosensitive Yim

hydrogel-type cultured epidermal allograft for deep second-degree burns. ${ }^{173}$

Yim

142. Study of the use of recombinant human granulocyte-macrophage colony-stimulating Yuan factor hydrogel externally to treat residual wounds of extensive deep partial-thickness burn. ${ }^{174}$

143. Effect of Olea ointment and Acetate Mafenide on burn wounds - A randomized clinical Zahmatkesh trial. ${ }^{175}$

2015

144. Effects of puerarin on the inflammatory role of burn-related procedural pain mediated Zhang by $\mathrm{P} 2 \times 7$ receptors. ${ }^{176}$

145. Effects of early enteral nutrition on the gastrointestinal motility and intestinal mucosal Zhang barrier of patients with burn-induced invasive fungal infection. ${ }^{81}$

146. Maximizing the safety of glycerol preserved human amniotic membrane as a biological Zidan dressing. ${ }^{177}$

147. Therapeutic Value of Blood Purification and Prognostic Utilities of Early Serum

Procalcitonin, C Reactive Protein, and Brain Natriuretic Peptide Levels in Severely Burned

Patients with Sepsis. ${ }^{178}$

2016

$\mathrm{Zu}$

A total of 9022 participants were recruited across the 140 studies (study protocols not included $n=7$ ). The number of patients recruited per trial ranged from 3 to 612 (median 50; IQR 30-88) for full RCTs and from 10 to 52 (median 21; IQR 16-28) for pilot studies. $50.4 \%$ of full RCTs recruited fewer than 50 participants (table 2). The majority $(89.7 \%$ ) of studies recruited (or planned to recruit) participants on one site alone. Of the $10.2 \%$ (15) of studies that were multicentre, nine $(60 \%)$ undertook research at only two or three sites. Thirty-two countries from the six global regions recruited patients into the 147 RCTs (table 2). The country that undertook the most studies was the USA with $22.4 \%$ (33), followed by Iran with $12.9 \%$ (19) and China with $10.9 \%$ (16) of published studies. Of the 32 countries, $59.3 \%$ (19) published only one trial in this time period. The most common trial interventions related to dressings and wound care $29.2 \%$
(43), followed by surgical technique $11.6 \%$ (17) and management of pain and itch $10.9 \%$ (16) (table 2).

\section{Outcomes}

A total of 1494 clinical outcomes were reported of which, after de-duplication, 955 different, unique outcomes remained. Of the 1494 outcomes reported, $27.7 \%$ (421) were common across two studies or more. Of these outcomes, $50.3 \%$ (78) appear in only two trials and $84.5 \%$ appear in five trials or fewer. The number of outcomes reported per trial varied from one to 37 (median 9; IQR 5,13) (table 3). No single outcome was reported across all 147 studies.

Outcome definition variation: Outcomes assessing the same healthcare issue were commonly defined differently. An example is burn wound healing which was defined in 166 different ways. Examples include: healing percentage 
Table 2 Randomised controlled tiral (RCT) detail

\section{Studies}

\begin{tabular}{lc}
\hline Number of RCTs & $127 / 147(86.4)$ \\
\hline Number of pilot studies & $13 / 147(8.8)$ \\
\hline Number of RCT protocols & $7 / 147(4.8)$ \\
\hline World region for recruitment &
\end{tabular}

\begin{tabular}{|lc|}
\hline Asia & $54 / 147(36.7)$ \\
\hline North America & $36 / 147(24.5)$ \\
\hline Europe & $26 / 147(17.7)$ \\
\hline Africa & $15 / 147(8.5)$ \\
\hline Latin America & $1 / 147(0.7)$ \\
\hline Australasia & $15 / 147(8.5)$ \\
\hline Year published & \\
\hline 2012 & $26 / 147(17.8)$ \\
\hline 2013 & $24 / 147(16.3)$ \\
\hline 2014 & $24 / 147(16.3)$ \\
\hline 2015 & $33 / 147(22.4)$ \\
\hline 2016 & $40 / 147(27.2)$ \\
\hline Number of sites & \\
\hline 1 & $132 / 147(89.8)$ \\
\hline $2-3$ & $9 / 147(6.1)$ \\
\hline $4-5$ & $2 / 147(1.4)$ \\
\hline$>5$ & $4 / 147(2.7)$ \\
\hline
\end{tabular}

Number of participants in full RCTs

\begin{tabular}{|lc}
\hline$<10$ & $4 / 127(3.1)$ \\
\hline $11-50$ & $62 / 127(48.8)$ \\
\hline $51-100$ & $39 / 127(30.7)$ \\
\hline $101-150$ & $11 / 127(8.7)$ \\
\hline$>150$ & $11 / 127(8.7)$ \\
\hline Participants recruited & \\
\hline$<18$ years & $24 / 147(16.3)$ \\
\hline$>18$ years & $59 / 147(40.1)$ \\
\hline Mixed age range & $25 / 147(17.0)$ \\
\hline Not stated & $34 / 147(23.1)$ \\
\hline N/A (protocol) & $5 / 147(3.4)$ \\
\hline Type of intervention & \\
\hline Dressings and wound care & $38 / 147(25.9)$ \\
\hline Surgical technique & $19 / 147(12.9)$ \\
\hline Treatment of pain or itch* & $16 / 147(10.9)$ \\
\hline Impact of exercise and rehabilitation & $13 / 147(8.8)$ \\
\hline Intensive care management & $10 / 147(6.8)$ \\
\hline Treatment of hypermetabolism & $8 / 147(5.4)$ \\
\hline Nutrition & $8 / 147(5.4)$ \\
\hline Scar management & $7 / 147(4.8)$ \\
\hline Treatment of inhalational injury & $3 / 147(2.0)$ \\
\hline Use of topical rHGM & $3 / 147(2.0)$ \\
\hline Use of rHGH & $3 / 147(2.0)$ \\
\hline & Continued \\
\hline
\end{tabular}

Table 2 Continued

\begin{tabular}{lc}
\hline & \multicolumn{1}{c}{ Studies } \\
\hline Sugar management & $2 / 148(2.0)$ \\
\hline Treatment of infection & $2 / 147(1.4)$ \\
Treatment of DVT & $2 / 147(1.4)$ \\
Blood management & $2 / 147(1.4)$ \\
Extracorporeal shock wave therapy & $2 / 147(1.4)$ \\
Platelet-rich plasma use & $2 / 147(1.4)$ \\
Others $\dagger$ & $7 / 147(5.4)$ \\
\hline
\end{tabular}

*Inc. distraction for dressing changes.

†Inc. levamisole, hyperbaric oxygen, fibroblast growth factor, oral calcium use, ketoconazole, low intensity laser.

$\ddagger$ No participants reported as study is a protocol.

DVT, deep vein thrombosis; N/A, not applicable; rHGH, recombinant human growth hormone; rHGM, recombinant Human Granulocyte-Macrophage colony-stimulating factor.

at specified timepoints, incidence of complete wound healing, incidence of $30 \%$ wound healing and length of time until $50 \%$ epithelialisation of burn wound. Similar variation in definition of burn wound infection existed with 79 unique outcome definitions including: bacterial colonisation of burn wound, days of antibiotics, incidence of local infection, incidence of positive wound cultures, periwound redness, rate of bacterial clearance from wound and number of inflammatory cells in the wound.

Outcome timing variation: There were 2743 outcomes measured if the same outcome measured at different timepoints across all the 147 RCTs are included; for example, size of burn wound measured at 1 week and again at 2 weeks, were recorded as different outcomes for this exercise. Of these, $76.9 \%$ (2109) were assessed at less than 6 months after injury, $16.6 \%$ (456) were measured after 6 months and before 3 years after injury, and only $5.1 \%$ (140) were measured at more than 3 years after injury (figure 2). The timing of outcome measurement was not reported for 38 outcomes.

Outcome domains: The 955 different clinical outcomes were organised into 54 domains (groups of similar outcomes). Table 4 categorises the domains into overarching categories and gives examples and total numbers of outcomes within each domain.

Table 3 Reported outcomes

\section{Number of outcomes per} study

\begin{tabular}{rl}
\hline 1 & $4 / 147(27.2 \%)$ \\
$2-5$ & $34 / 147(23.1 \%)$ \\
$6-10$ & $53 / 147(36.1 \%)$ \\
$11-20$ & $41 / 147(27.9 \%)$ \\
$>20$ & $15 / 147(10.2 \%)$ \\
\hline
\end{tabular}




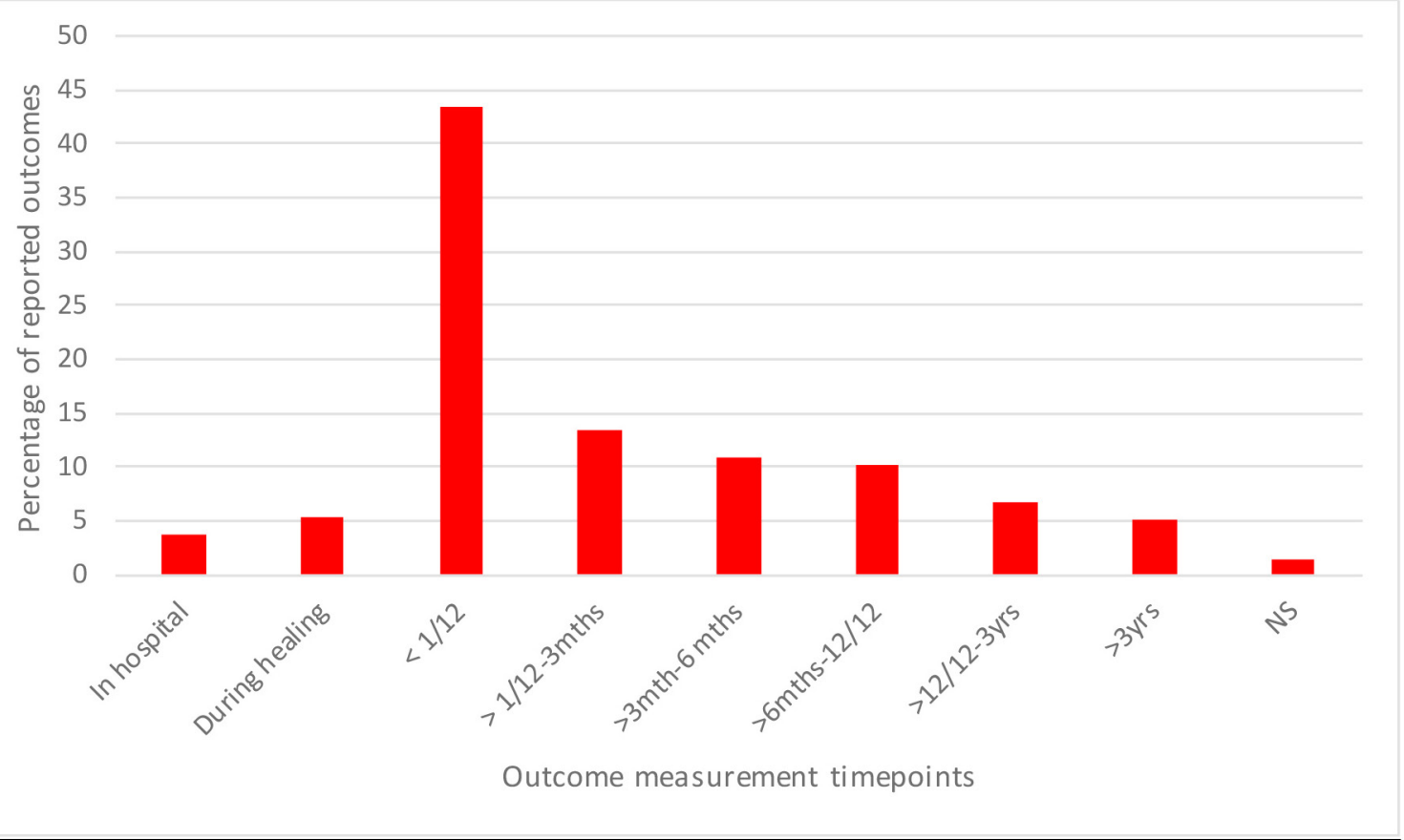

Figure 2 Reported timepoint at which outcome was assessed. mths, months; NS, not stated; yrs, years.

\section{DISCUSSION}

This systematic review aimed to examine outcome reporting in RCTs in burn care. Of the 147 included studies, 1494 outcomes were identified with 955 of these unique. There was overlap in terminology, inconsistent definitions and variation in time after injury at which the outcomes were measured. Only $30 \%$ of the outcomes reported were included in more than one study. There was no single outcome reported across all 147 trials. Commonly-reported outcomes were defined differently between trials, such as burn wound healing which was defined in 166 different ways. Such heterogeneity of outcome reporting across trials will limit evidence synthesis and result in research wastage.

The findings in this review have been seen elsewhere in the burns-specific and other clinical literature. A Cochrane review of 30 RCTs concluded that it was impossible to draw conclusions about burn dressing effectiveness, as the trials evaluated a variety of clinical outcomes. ${ }^{18} 179$ Over the same period as this review, nine Cochrane reviews have had direct relevance to the management of patients with burns. ${ }^{18}{ }^{180-187}$ None could draw firm conclusions due to methodological issues including heterogeneity of outcome reporting. Heterogeneity is found in the reporting of outcomes relating to critical care, neurological illness, breast reconstruction surgery, prostate cancer, hip and knee replacement, oesophagectomy surgery, low back pain and in cardiac arrest trials among others. ${ }^{188-195}$ Variation in the definitions of outcomes has also been found within published studies of other healthcare areas. A systematic review of 90 papers reporting wound infection after general surgical procedures identified 41 definitions for wound infection itself, including three published by expert groups. ${ }^{196}$ Similarly, a total of 56 definitions were identified from 97 studies reporting anastomotic leak rates after gastrointestinal surgery despite publication of a standard definition 2 years before the beginning of the review. ${ }^{197}$

In this review, we identified and agreed the grouping of the 955 unique outcomes into 54 outcome domains. There is no agreement between COS reviewers about how best to classify outcomes into domains. Williamson published a taxonomy of categorising outcome domains. ${ }^{198}$ Other authors have suggested different ways of doing this, all addressing different needs ${ }^{32} 33199$ ). In the Williamson taxonomy, the authors state that of 99 COS studies, 21 applied their own approach to outcome classification and only six used an existing system. As we had identified a large number of different clinical burn outcomes and as the outcomes we extracted did not clearly fall within the Williamson taxonomy, we decided to use our own approach to domain classification. We used five multidisciplinary researchers and a patient working independently, and subsequently together, to bring different views and as little bias as possible to the process.

A solution to the above described variation in outcome reporting across trials, is the development of a COS. ${ }^{21200} 201$ A COS is a minimum set of the most important outcomes, agreed and recommended for measurement in all trials for a particular condition. ${ }^{31}{ }^{32}$ While not limiting choice, a COS will prespecify a set of outcomes to ensure consistency of reporting and the ability to collate evidence into systematic reviews by allowing researchers to compare 'like with like'. ${ }^{33}$ Trials can still select additional outcomes in addition to the minimum core set. This approach has been shown to improve the consistency of outcome reporting. ${ }^{202}{ }^{203}$ Although there 
Table 4 Outcome category, domains and examples of outcomes

\begin{tabular}{|c|c|c|c|}
\hline Outcome category & Outcome domain & Outcome examples & $\begin{array}{l}\text { outcomes per } \\
\text { domain }\end{array}$ \\
\hline \multirow[t]{17}{*}{ Patient-reported } & Ability to carry out daily tasks & Functional level of independence & 1 \\
\hline & $\begin{array}{l}\text { Anxiety about medical procedures and } \\
\text { appointments }\end{array}$ & $\begin{array}{l}\text { Pain anxiety } \\
\text { Anxiety before dressing changes }\end{array}$ & 4 \\
\hline & Generalised anxiety & General anxiety & 1 \\
\hline & Appearance & $\begin{array}{l}\text { Facial symmetry } \\
\text { Overall scar appearance }\end{array}$ & 3 \\
\hline & Blister fluid & Amount of exudate & 3 \\
\hline & Burden of care & $\begin{array}{l}\text { Frequency of dressing changes } \\
\text { Time taken for daily wound cleaning }\end{array}$ & 7 \\
\hline & Comfort of dressings & Dressing comfort & 1 \\
\hline & Psychological well-being & Improvement in well-being & 1 \\
\hline & Mental ability & & 2 \\
\hline & Quality and quantity of sleep & $\begin{array}{l}\text { Quantity of sleep } \\
\text { Incidence of sleep disturbance }\end{array}$ & 17 \\
\hline & Effect of scar on movement (contractures) & Cognitive performance & 3 \\
\hline & Return to work/school or previous function & Return to work or previous function & 1 \\
\hline & Burn wound pain & $\begin{array}{l}\text { Wound pain intensity at baseline } \\
\text { Pain tolerance }\end{array}$ & 29 \\
\hline & Donor site pain & $\begin{array}{l}\text { Donor site pain at rest } \\
\text { Donor site pain while walking }\end{array}$ & 6 \\
\hline & Pain during procedures & $\begin{array}{l}\text { Wound pain at dressing changes } \\
\text { Pain during hydrotherapy }\end{array}$ & 14 \\
\hline & Scar pain & $\begin{array}{l}\text { Functional scar pain } \\
\text { Incidence of neuropathic pain }\end{array}$ & 13 \\
\hline & Itch & $\begin{array}{l}\text { Baseline pruritus } \\
\text { Itch severity reduction }\end{array}$ & 24 \\
\hline \multirow[t]{14}{*}{ Pathophysiological } & Ability to fight infection & $\begin{array}{l}\text { Change in IgA } \\
\text { IL-1beta in blood } \\
\text { Serum interferon gamma levels }\end{array}$ & 36 \\
\hline & Body weight maintenance & $\begin{array}{l}\text { Incidence of weight loss } \\
\text { Body weight decrease from baseline }\end{array}$ & 26 \\
\hline & Bone strength & $\begin{array}{l}\text { Bone mineral density } \\
\text { Incidence of osteoporosis }\end{array}$ & 30 \\
\hline & Breathing and lungs & $\begin{array}{l}\text { Forced expiratory volume in } 1 \mathrm{~s} \\
\text { Functional residual capacity }\end{array}$ & 27 \\
\hline & Donor site problems after healing & $\begin{array}{l}\text { Donor site pigmentation } \\
\text { Sensation of donor site }\end{array}$ & 24 \\
\hline & Effect of burn on genes & Gene expression patterns & 1 \\
\hline & Effect of burn on how the body uses energy & $\begin{array}{l}\text { Change in percentage of predicted resting energy } \\
\text { expenditure }\end{array}$ & 2 \\
\hline & Effect on heart and blood circulation & $\begin{array}{l}\text { Incidence of cardiomegaly } \\
\text { Number of patients requiring norepinephrine }\end{array}$ & 28 \\
\hline & Fitness & $\begin{array}{l}\text { Maximum aerobic capacity } \\
\text { Exercise maximum minute ventilation }\end{array}$ & 12 \\
\hline & Growth in children & $\begin{array}{l}\text { Duration of growth arrest } \\
\text { Percentage change in height }\end{array}$ & 10 \\
\hline & How well muscles work & $\begin{array}{l}\text { Facial mimic function } \\
\text { Change in muscle function }\end{array}$ & 9 \\
\hline & Mobility & $\begin{array}{l}\text { Stride length } \\
\text { Knee range of motion }\end{array}$ & 22 \\
\hline & Kidney function & $\begin{array}{l}\text { Incidence of acute kidney injury } \\
\text { Requirement for renal replacement therapy }\end{array}$ & 17 \\
\hline & Liver function & $\begin{array}{l}\text { Hepatic function } \\
\text { Ammonia levels }\end{array}$ & 11 \\
\hline
\end{tabular}


Table 4 Continued

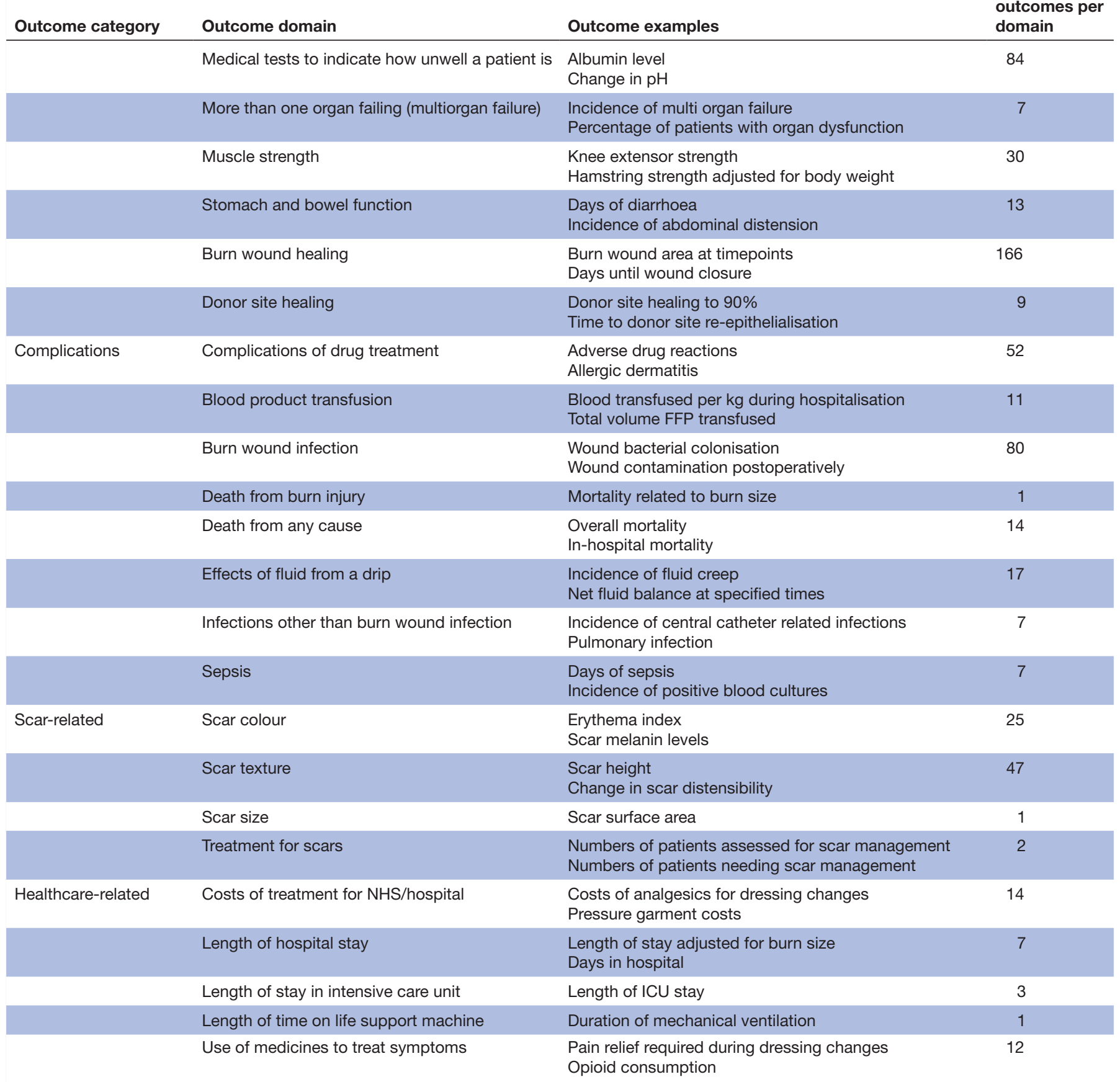

FFP, fresh frozen plasma; ICU, intensive care unit; IL, interleukin; NHS, National Health Service.

is no $\operatorname{COS}$ for burn care, work was undertaken in 2008 to agree a set of burn outcome domains. ${ }^{198}$ However, the work was undertaken by a small group of clinicians, lacked patient involvement and reported little methodological detail. ${ }^{204}$ Considerable work to develop COS methodology has also been undertaken since this publication. ${ }^{205} 206$ The COMET Initiative disseminates resources for COS development and supports methodological developments in this area. ${ }^{207} 208$ COMET recommends a four-step process to develop a COS: (a) agreement of the scope, (b) assessment of the need, (c) development of a protocol and finally (d) agreement of the COS. ${ }^{15}$ This systematic review has satisfied the first two phases for the development of a burn care COS. The final phase encompasses organising a comprehensive long-list of all potential outcomes into domains (of which the clinical domains for burn care are listed in table 4) and prioritising these domains using a consensus process. ${ }^{209-211}$

The strengths of this review are that the protocol and data extraction proforma were prespecified and the literature search was systematic and comprehensive, including 
four major healthcare trial databases. To account for multidisciplinary perspectives, two researchers, two clinicians and a patient were involved in the domain process. It is also novel because it is the first to demonstrate, in detail and using systematic methodology, the scale of the heterogeneity of outcome reporting in burn care research. Limitations include the exclusion of publications in languages other than English. However, international publications were included to reduce the risk of selection bias. The search was also time-limited which may have excluded outcomes from older studies. The reason for the time limitation was to identify research relevant to modern burn care. The search was also limited to trials reporting clinical outcomes. Other work is in progress to assess patient-reported outcomes in burn care research. This was a review undertaken systematically to a prespecified protocol. However, a formal quality assessment of studies was not undertaken, as we were researching the reporting of outcomes and not attempting to analyse the effects of interventions. A COS for burn care research would address the issue of heterogeneity of outcome reporting between trials, lead to research that is more likely to measure relevant outcomes, enhance the value of burn care systematic reviews and reduce research waste.

\section{CONCLUSION}

We have shown that multiple different unique outcomes are reported in trials of burn care interventions. Different definitions are used to assess the same outcome issue and outcomes are measured at different time points after injury. This heterogeneity and inconsistency in outcome reporting prevent effective evidence synthesis and limits the quality of evidence available for clinical decision-making. Our review demonstrates that until greater consistency is achieved in outcome reporting in trials, it is unlikely that clinicians will be able to synthesise evidence across studies to understand the effects of surgical and non-surgical treatments following burn injury. It is recommended that a burn care COS is developed to support the effective synthesis of trial data and allow more informed clinical decision-making for the benefit of patients.

Acknowledgements We would like to thank Dr Jason Wasiak, Senior Research Fellow, University of Melbourne, Monash University, Medical School, for his invaluable help in critically editing the paper. We would like to also thank Ms Joanna Hooper, senior outreach librarian and the University Hospitals Bristol NHS Foundation Trust medical library for their help in accessing articles.

Contributors AEY wrote the paper and conceived the project with the support of JMB. JMB and SBr edited and critically revised the article. AD contributed to data extraction and edited the paper. SBI assisted in the domain name choice and article editing and readability. All authors have read and approved the manuscript.

Funding This article/paper/report presents independent research funded by the National Institute for Health Research (NIHR) Doctoral Research Fellowship DRF-2016-09-031. JMB is part-funded by the Medical Research Council ConDuCT-II Hub (Collaboration and innovation for Difficult and Complex randomised controlled Trials In Invasive procedures—MR/K025643/1). The study was also supported by the NIHR Biomedical Research Centre at the University Hospitals Bristol NHS Foundation Trust and the University of Bristol.

Disclaimer The views expressed are those of the author(s) and not necessarily those of the NHS, the NIHR or the Department of Health.
Competing interests JB is an NIHR Senior Investigator. All other authors declare no competing interests.

Patient consent for publication Not required.

Ethics approval South West Frenchay Research Ethics Committee (ref: 17/ SW/0025 IRAS 221625).

Provenance and peer review Not commissioned; externally peer reviewed.

Data sharing statement No further data are available.

Open access This is an open access article distributed in accordance with the Creative Commons Attribution 4.0 Unported (CC BY 4.0) license, which permits others to copy, redistribute, remix, transform and build upon this work for any purpose, provided the original work is properly cited, a link to the licence is given, and indication of whether changes were made. See: https://creativecommons.org/ licenses/by/4.0/.

\section{REFERENCES}

1. Mock C, Peck M, Peden M, et al. A WHO plan for burn prevention and care. Geneva: World Health Organization, 2008.

2. Peck M, Molnar J, Swart D. A global plan for burn prevention and care. Bull World Health Organ 2009;87:802-3.

3. Atiyeh BS, Hayek SN, Gunn SW. New technologies for burn wound closure and healing--review of the literature. Burns 2005;31:944-56.

4. Jeschke MG, Shahrokhi S, Finnerty CC, et al. Wound coverage technologies in burn care: established techniques. J Burn Care Res 2018;39:313-8.

5. Rowan MP, Cancio LC, Elster EA, et al. Burn wound healing and treatment: review and advancements. Crit Care 2015;19:243.

6. Sackett DL, Rosenberg WM, Gray JA, et al. Evidence based medicine: what it is and what it isn't. BMJ 1996;312:71-2.

7. Dickinson HD. Evidence-based decision-making: an argumentative approach. Int J Med Inform 1998;51:71-81.

8. Every-Palmer S, Howick J. How evidence-based medicine is failing due to biased trials and selective publication. J Eval Clin Pract 2014;20:908-14.

9. Muir Gray J. Evidence-based healthcare: how to make health policy and management decisions. London: Churchill Livingstone., 1997:53.

10. Centre for evidence based medicine. CEBM Levels of evidence. 2011. https://www.cebm.net/wp-content/uploads/2014/06/CEBMLevels-of-Evidence-2.1.pdf

11. Flores $\mathrm{O}$, Stockton K, Roberts JA, et al. The efficacy and safety of adrenergic blockade after burn injury: a systematic review and meta-analysis. J Trauma Acute Care Surg 2016;80:146-55.

12. Avni T, Levcovich A, Ad-El DD, et al. Prophylactic antibiotics for burns patients: systematic review and meta-analysis. BMJ 2010;340:c241.

13. Aziz Z, Abu SF, Chong NJ. A systematic review of silver-containing dressings and topical silver agents (used with dressings) for burn wounds. Burns 2012;38:307-18.

14. Liberati A, Altman DG, Tetzlaff J, et al. The PRISMA statement for reporting systematic reviews and meta-analyses of studies that evaluate health care interventions: explanation and elaboration. PLoS Med 2009;6:e1000100.

15. Williamson PR, Altman DG, Bagley $\mathrm{H}$, et al. The COMET Handbook: version 1.0. Trials 2017;18:280.

16. Chan AW, Krleza-Jerić K, Schmid I, et al. Outcome reporting bias in randomized trials funded by the Canadian Institutes of Health Research. Can Med Assoc J 2004;171:735-40.

17. van Baar ME, Essink-Bot ML, Oen IM, et al. Functional outcome after burns: a review. Burns 2006;32:1-9.

18. Wasiak J, Cleland H, Campbell F, et al. Dressings for superficial and partial thickness burns. Cochrane Database Syst Rev 2013;18.

19. Lawrence JW, Mason ST, Schomer K, et al. Epidemiology and impact of scarring after burn injury: a systematic review of the literature. J Burn Care Res 2012;33:136-46.

20. Sinha IP, Smyth RL, Williamson PR. Using the Delphi technique to determine which outcomes to measure in clinical trials: recommendations for the future based on a systematic review of existing studies. PLoS Med 2011;8:e1000393.

21. Williamson PR, Altman DG, Blazeby JM, et al. Developing core outcome sets for clinical trials: issues to consider. Trials 2012;13:132.

22. Klein MB, Goverman J, Hayden DL, et al. Benchmarking outcomes in the critically injured burn patient. Ann Surg 2014;259:833-41.

23. Pereira C, Murphy K, Herndon D. Outcome measures in burn care. Is mortality dead? Burns 2004;30:761-71. 
24. Verbelen J, Hoeksema H, Heyneman A, et al. Aquacel Ag dressing versus Acticoat ${ }^{\mathrm{TM}}$ dressing in partial thickness burns: a prospective, randomized, controlled study in 100 patients. Part 1: burn wound healing. Burns 2014;40:416-27.

25. Hop MJ, Polinder S, van der Vlies $\mathrm{CH}$, et al. Costs of burn care: a systematic review. Wound Repair Regen 2014;22:436-50.

26. Azzopardi EA, Azzopardi E, Camilleri L, et al. Gram negative wound infection in hospitalised adult burn patients--systematic review and metanalysis-. PLoS One 2014;9:e95042.

27. Griffiths HR, Thornton KL, Clements CM, et al. The cost of a hot drink scald. Burns 2006;32:372-4.

28. Holavanahalli RK, Helm PA, Kowalske KJ. Long-term outcomes in patients surviving large burns: the musculoskeletal system. J Burn Care Res 2016;37:243-54.

29. Young A, Brookes S, Rumsey N, et al. Agreement on what to measure in randomised controlled trials in burn care: study protocol for the development of a core outcome set. BMJ Open 2017;7:e017267.

30. Hopkins JC, Howes N, Chalmers K, et al. Outcome reporting in bariatric surgery: an in-depth analysis to inform the development of a core outcome set, the BARIACT Study. Obes Rev 2015;16:88-106.

31 . United Nations. www.un.org/esa/population/publications/ worldageing19502050/pdf/96annexii.pdf.

32. Smith V, Clarke M, Williamson P, et al. Survey of new 2007 and 2011 Cochrane reviews found $37 \%$ of prespecified outcomes not reported. J Clin Epidemiol 2015;68:237-45.

33. Davey J, Turner RM, Clarke MJ, et al. Characteristics of metaanalyses and their component studies in the Cochrane Database of Systematic Reviews: a cross-sectional, descriptive analysis. BMC Med Res Methodol 2011;11:160.

34. Abedini F, Ahmadi A, Yavari A, et al. Comparison of silver nylon wound dressing and silver sulfadiazine in partial burn wound therapy. Int Wound J 2013;10:573-8.

35. Adhya A, Bain J, Ray O, et al. Healing of burn wounds by topical treatment: a randomized controlled comparison between silver sulfadiazine and nano-crystalline silver. J Basic Clin Pharm 2014;6:29.

36. Ahuja RB, Bansal P, Pradhan GS, et al. An analysis of deep vein thrombosis in burn patients (Part 1): comparison of D-dimer and Doppler ultrasound as screening tools. Burns 2016;42:1686-92.

37. Ahuja RB, Bansal P, Pradhan GS, et al. An analysis of deep vein thrombosis in burn patients (part II): a randomized and controlled study of thrombo-prophylaxis with low molecular weight heparin. Burns 2016;42:1693-8.

38. Ahuja RB, Gupta GK. A four arm, double blind, randomized and placebo controlled study of pregabalin in the management of postburn pruritus. Burns 2013;39:24-9.

39. Ali A, Herndon DN, Mamachen A, et al. Propranolol attenuates hemorrhage and accelerates wound healing in severely burned adults. Crit Care 2015;19:217.

40. Ali ZM, El-Refay BH, Ali RR. Aerobic exercise training in modulation of aerobic physical fitness and balance of burned patients. J Phys Ther Sci 2015;27:585-9.

41. Aramwit $\mathrm{P}$, Palapinyo $\mathrm{S}$, Srichana $\mathrm{T}$, et al. Silk sericin ameliorates wound healing and its clinical efficacy in burn wounds. Arch Dermatol Res 2013;305:585-94.

42. As'adi K, Emami SA, Salehi SH, et al. A Randomized controlled trial comparing endoscopic-assisted versus open neck tissue expander placement in reconstruction of post-burn facial scar deformities. Aesthetic Plast Surg 2016;40:526-34.

43. Assadian O, Arnoldo B, Purdue G, et al. A prospective, randomised study of a novel transforming methacrylate dressing compared with a silver-containing sodium carboxymethylcellulose dressing on partial-thickness skin graft donor sites in burn patients. Int Wound $J$ 2015;12:351-6.

44. Bailey JK, Burkes SA, Visscher MO, et al. Multimodal quantitative analysis of early pulsed-dye laser treatment of scars at a pediatric burn hospital. Dermatol Surg 2012;38:1490-6.

45. Béchir M, Puhan MA, Fasshauer M, et al. Early fluid resuscitation with hydroxyethyl starch 130/0.4 (6\%) in severe burn injury: a randomized, controlled, double-blind clinical trial. Crit Care 2013;17:R299.

46. Black JS, Drake DB. A prospective randomized trial comparing silver sulfadiazine cream with a water-soluble polyantimicrobial gel in partial-thickness burn wounds. Plast Surg Nurs 2015;35:46-9.

47. Bloemen MC, van der Wal MB, Verhaegen PD, et al. Clinical effectiveness of dermal substitution in burns by topical negative pressure: a multicenter randomized controlled trial. Wound Repair Regen 2012;20:797-805
48. Blome-Eberwein S, Abboud M, Lozano DD, et al. Effect of subcutaneous epinephrine/saline/local anesthetic versus saline-only injection on split-thickness skin graft donor site perfusion, healing, and pain. J Burn Care Res 2013;34:e80-e86.

49. Brown M, Dalziel SR, Herd E, et al. A randomized controlled study of silver-based burns dressing in a pediatric emergency department. J Burn Care Res 2016;37:e340-e347.

50. Brown NJ, David M, Cuttle L, et al. Cost-effectiveness of a nonpharmacological intervention in pediatric burn care. Value Health 2015;18:631-7.

51. Brown NJ, Kimble RM, Rodger S, et al. Play and heal: randomized controlled trial of Ditto ${ }^{\mathrm{TM}}$ intervention efficacy on improving reepithelialization in pediatric burns. Burns 2014;40:204-13.

52. Carr JA, Crowley N. Prophylactic sequential bronchoscopy after inhalation injury: results from a three-year prospective randomized trial. Eur J Trauma Emerg Surg 2013;39:177-83.

53. Chahed J, Ksia A, Selmi W, et al. Burns injury in children: is antibiotic prophylaxis recommended? Afr J Paediatr Surg 2014;11:323.

54. Chen G, Shao H, Pan X. A randomized controlled trial to compare the effects of liquid versus powdered recombinant human growth hormone in treating patients with severe burns. Biomed Rep 2016;4:551-6.

55. Chen L, Meng K, Su W, et al. The Effect of Continuous Sedation Therapy on Immunomodulation, Plasma Levels of Antioxidants, and Indicators of Tissue Repair in Post-Burn Sepsis Patients. Cell Biochem Biophys 2015;73:473-8.

56. Chen X, Feng X, Xie J, et al. Application of acellular dermal xenografts in full-thickness skin burns. Exp Ther Med 2013;6:194-8.

57. Chester SJ, Stockton K, De Young A, et al. Effectiveness of medica hypnosis for pain reduction and faster wound healing in pediatric acute burn injury: study protocol for a randomized controlled trial. Trials 2016;17:223.

58. Chi YF, Chai JK, Luo HM, et al. Safety of recombinant human granulocyte-macrophage colony-stimulating factor in healing pediatric severe burns. Genet Mol Res 2015;14:2735-41.

59. Cho YS, Choi YH. Comparison of three cooling methods for burn patients: a randomized clinical trial. Burns 2017:43:502-8.

60. Cho YS, Jeon JH, Hong A, et al. The effect of burn rehabilitation massage therapy on hypertrophic scar after burn: a randomized controlled trial. Burns 2014;40:1513-20.

61. Cho YS, Joo SY, Cui H, et al. Effect of extracorporeal shock wave therapy on scar pain in burn patients: a prospective, randomized, single-blind, placebo-controlled study. Medicine 2016;95:e4575.

62. Chong SJ, Kan EM, Song C, et al. Characterization of early thermal burns and the effects of hyperbaric oxygen treatment: a pilot study. Diving Hyperb Med 2013;43:157-61.

63. Clayton RP, Wurzer P, Andersen CR, et al. Effects of different duration exercise programs in children with severe burns. Burns 2017; $43: 796-803$

64. Cone L, Gottschlich M, Khoury J, et al. The effect of healing touch on sleep patterns of pediatric burn patients: a prospective pilot study. J Sleep Disor 2014;6:2.

65. Csontos C, Rezman B, Foldi V, et al. Effect of N-acetylcysteine treatment on oxidative stress and inflammation after severe burn. Burns 2012;38:428-37.

66. Cucereanu-Bădică I, Luca I, Negreș S, et al. The effects of intravenous glutamine supplementation in severely burned multiple traumatized patients. Farmacia 2013;61:212-9.

67. Donovan ML, Muller MJ, Simpson C, et al. Interim pressure garment therapy $(4-6 \mathrm{mmHg})$ and its effect on donor site healing in burn patients: study protocol for a randomised controlled trial. Trials 2016;17:214

68. Ebid AA, Ahmed MT, Mahmoud Eid M, et al. Effect of whole body vibration on leg muscle strength after healed burns: a randomized controlled trial. Burns 2012;38:1019-26.

69. Ebid AA, El-Shamy SM, Draz AH. Effect of isokinetic training on muscle strength, size and gait after healed pediatric burn: a randomized controlled study. Burns 2014;40:97-105.

70. Ebid AA, Omar MT, Abd El Baky AM. Effect of 12-week isokinetic training on muscle strength in adult with healed thermal burn. Burns 2012;38:61-8.

71. Edionwe J, Hess C, Fernandez-Rio J, et al. Effects of whole-body vibration exercise on bone mineral content and density in thermally injured children. Burns 2016;42:605-13.

72. Ehmer AIR, Khan Mh;, Hasan M;, et al. Efficacy of platelet rich plasma application in comparison to conventional dressing therapy in partial thickness burn wound. Medical Forum Monthly 2014;25:27-30. 
73. El-Ghazely MH, Mahmoud WH, Atia MA, et al. Effect of probiotic administration in the therapy of pediatric thermal burn. Ann Burns Fire Disasters 2016;29:268

74. Elsharnouby NM, Eid HEA, Abou Elezz NF, et al. Heparin/Nacetylcysteine: an adjuvant in the management of burn inhalation injury. J Crit Care 2014;29:182.e1-182.e4.

75. Fatemi MJ, Salehi $\mathrm{H}$, Akbari $\mathrm{H}$, et al. The effect of levamisole on mortality rate among patients with severe burn injuries. $J$ Res Med Sci 2013;18:795

76. Finnerty CC, Ali A, McLean J, et al. Impact of stress-induced diabetes on outcomes in severely burned children. J Am Coll Surg 2014;218:783-95.

77. Gardien KL, Marck RE, Bloemen MC, et al. Outcome of burns treated with autologous cultured proliferating epidermal cells: a prospective randomized multicenter intrapatient comparative trial. Cell Transplant 2016;25:437-48

78. Gee Kee EL, Kimble RM, Cuttle L, et al. Randomized controlled trial of three burns dressings for partial thickness burns in children. Burns 2015;41:946-55

79. Genuino GA, Baluyut-Angeles KV, Espiritu AP, et al. Topical petrolatum gel alone versus topical silver sulfadiazine with standard gauze dressings for the treatment of superficial partial thickness burns in adults: a randomized controlled trial. Burns 2014; $40: 1267-73$

80. Glas GJ, Muller J, Binnekade JM, et al. HEPBURN - investigating the efficacy and safety of nebulized heparin versus placebo in burn patients with inhalation trauma: study protocol for a multi-center randomized controlled trial. Trials 2014:15:91.

81. Zhang $Y$, Gu F, Wang F, et al. Effects of early enteral nutrition on the gastrointestinal motility and intestinal mucosal barrier of patients with burn-induced invasive fungal infection. Pak J Med Sci 2016;32:599.

82. Günter $\mathrm{Cl}$, Bader A, Dornseifer $\mathrm{U}$, et al. A multi-center study on the regenerative effects of erythropoietin in burn and scalding injuries: study protocol for a randomized controlled trial. Trials 2013;14:124

83. Hardee JP, Porter C, Sidossis LS, et al. Early rehabilitative exercise training in the recovery from pediatric burn. Med Sci Sports Exerc 2014;46:1710-6.

84. Hayashida K, Akita S. Quality of pediatric second-degree burn wound scars following the application of basic fibroblast growth factor: results of a randomized, controlled pilot study. Ostomy Wound Manage 2012;58:32

85. Herndon DN, Rodriguez NA, Diaz EC, et al. Long-term propranolol use in severely burned pediatric patients: a randomized controlled study. Ann Surg 2012;256:402.

86. Herndon DN, Voigt CD, Capek KD, et al. Reversal of growth arrest with the combined administration of oxandrolone and propranolol in severely burned children. Ann Surg 2016;264:421-8.

87. Hop MJ, Stekelenburg CM, Hiddingh J, et al. Cost-effectiveness of laser doppler imaging in burn care in The Netherlands: a randomized controlled trial. Plast Reconstr Surg 2016;137:166e-76.

88. Hsu KC, Chen LF, Hsiep PH. Effect of music intervention on burn patients' pain and anxiety during dressing changes. Burns 2016;42:1789-96.

89. Huang G, Liang B, Liu G, et al. Low dose of glucocorticoid decreases the incidence of complications in severely burned patients by attenuating systemic inflammation. J Crit Care 2015;30:436.e7-436.e11.

90. Hyland EJ, D'Cruz R, Harvey JG, et al. An assessment of early child life therapy pain and anxiety management: a prospective randomised controlled trial. Burns 2015;41:1642-52.

91. Hyland EJ, D'Cruz R, Menon S, et al. Prospective, randomised controlled trial comparing Versajet ${ }^{\mathrm{TM}}$ hydrosurgery and conventional debridement of partial thickness paediatric burns. Burns 2015;41:700-7.

92. Isaac K, Umraw N, Cartotto R. Construction of skin graft seams in burn patients: a prospective randomized double-blinded study. $J$ Burn Care Res 2016;37:397-403.

93. Jang KU, Choi JS, Mun JH, et al. Multi-axis shoulder abduction splint in acute burn rehabilitation: a randomized controlled pilot trial. Clin Rehabil 2015;29:439-46.

94. Jeschke MG, Abdullahi A, Burnett M, et al. Glucose control in severely burned patients using metformin: an interim safety and efficacy analysis of a phase ii randomized controlled trial. Ann Surg 2016;264:518-27.

95. Jeschke MG, Williams FN, Finnerty CC, et al. The effect of ketoconazole on post-burn inflammation, hypermetabolism and clinical outcomes. PLoS One 2012;7:e35465.

96. Kaheni S, Sadegh Rezai M, Bagheri-Nesami M, et al. The effect of Distraction Technique on the pain of Dressing change among 3-6 year-old children. Int J Pediatr 2016;4:1603-10.
97. Keorochana K, Chaiyasuk P, Muangman P. Prospective randomizecontrolled comparison between silicone plus herbal extract gel versus Aloe vera gel for burn scar prophylaxis. Wound Medicine 2015:9:1-4.

98. Kibor DK, Nyaim OE, Wanjeri K. Effects of enteral glutamine supplementation on reduction of infection in adult patients with severe burns. East Afr Med J 2014:91:33-6.

99. Kim JB, Cho YS, Jang KU, et al. Effects of sustained release growth hormone treatment during the rehabilitation of adult severe burn survivors. Growth Horm IGF Res 2016;27:1-6.

100. Kipping B, Rodger S, Miller K, et al. Virtual reality for acute pain reduction in adolescents undergoing burn wound care: a prospective randomized controlled trial. Burns 2012;38:650-7.

101. Kolmus AM, Holland AE, Byrne MJ, et al. The effects of splinting on shoulder function in adult burns. Burns 2012;38:638-44.

102. Lagus H, Sarlomo-Rikala M, Böhling T, et al. Prospective study on burns treated with Integra ${ }$, a cellulose sponge and split thickness skin graft: comparative clinical and histological study--randomized controlled trial. Burns 2013;39:1577-87.

103. Lairet KF, Baer D, Leas ML, et al. Evaluation of an oxygen-diffusion dressing for accelerated healing of donor-site wounds. J Burn Care Res 2014;35:214-8.

104. Lak S, Ostadrahimi A, Nagili B, et al. Anti-inflammatory effect of taurine in burned patients. Adv Pharm Bull 2015;5:531-6.

105. Lewis PA, Wright $\mathrm{K}$, Webster $\mathrm{A}$, et al. A randomized controlled pilot study comparing aqueous cream with a beeswax and herbal oil cream in the provision of relief from postburn pruritus. J Burn Care Res 2012;33:e195-e200.

106. Li X, Meng X, Wang X, et al. Human acellular dermal matrix allograft: a randomized, controlled human trial for the long-term evaluation of patients with extensive burns. Burns 2015;41:689-99.

107. López-Rodríguez L, de la Cal MA, García-Hierro P, et al. Selective digestive decontamination attenuates organ dysfunction in critically III Burn Patients. Shock 2016;46:492-7.

108. Lorello DJ, Peck M, Albrecht M, et al. Results of a prospective randomized controlled trial of early ambulation for patients with lower extremity autografts. J Burn Care Res 2014;35:1-6.

109. Mabrouk A, Boughdadi NS, Helal HA, et al. Moist occlusive

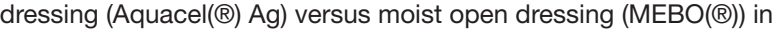
the management of partial-thickness facial burns: a comparative study in Ain Shams University. Burns 2012;38:396-403.

110. Maghsoudi H, Nezami N, Mirzajanzadeh M. Enhancement of burn wounds healing by platelet dressing. Int J Burns Trauma 2013;3:96

111. Mahmoud WH, Mostafa W, Abdel-Khalek AH, et al. Effect of immune-enhancing diets on the outcomes of patients after major burns. Ann Burns Fire Disasters 2014;27:192.

112. Malin EW, Galin CM, Lairet KF, et al. Silver-coated nylon dressing plus active DC microcurrent for healing of autogenous skin donor sites. Ann Plast Surg 2013;71:481-4.

113. Marck RE, Gardien KL, Stekelenburg CM, et al. The application of platelet-rich plasma in the treatment of deep dermal burns: A randomized, double-blind, intra-patient controlled study. Wound Repair Regen 2016;24:712-20.

114. Mayes T, Gottschlich MM, James LE, et al. Clinical safety and efficacy of probiotic administration following burn injury. J Burn Care Res 2015;36:92-9.

115. McBride CA, Kimble RM, Stockton K. Three donor site dressings in pediatric split-thickness skin grafts: study protocol for a randomised controlled trial. Trials 2015;16:43.

116. Moghazy AM, Adly OA, Elbadawy MA, et al. Evaluation of who oral rehydration solution (ORS) and salt tablets in resuscitating adult patients with burns covering more than $15 \%$ of total body surface area (TBSA). Ann Burns Fire Disasters 2016;29:43.

117. Mohamed SA-R, Mohamed NN. Efficacy and adverse events of early high-frequency oscillatory ventilation in adult burn patients with acute respiratory distress syndrome. Egypt $J$ Anaesth 2016;32:421-9.

118. Mohammadi AA, Johari HG, Eskandari S. Effect of amniotic membrane on graft take in extremity burns. Burns 2013;39:1137-41.

119. Moravvej H, Hormozi AK, Hosseini SN, et al. Comparison of the application of allogeneic fibroblast and autologous mesh grafting with the conventional method in the treatment of third-degree burns. J Burn Care Res 2016;37:e90-e95

120. Mowafy ZM, Monem MA, Zoheiry IMI, et al. Effect of low-intensity laser on the neuropathic common peroneal nerve post burn.

121. Muangman P, Praditsuktavorn B, Chinaroonchai K, et al. Clinical efficacy test of polyester containing herbal extract dressings in burn wound healing. Int J Low Extrem Wounds 2016;15:203-12.

122. Müller Dittrich MH, Brunow de Carvalho W, Lopes Lavado E. Evaluation of the "Early" use of albumin in children with extensive 
burns: a randomized controlled trial. Pediatr Crit Care Med 2016;17:e280-e6.

123. Najmi M, Vahdat Shariatpanahi Z, Tolouei M, et al. Effect of oral olive oil on healing of $10-20 \%$ total body surface area burn wounds in hospitalized patients. Burns 2015;41:493-6.

124. Nedelec B, Rachelska G, Parnell LK, et al. Double-blind, randomized, pilot study assessing the resolution of postburn pruritus. J Burn Care Res 2012;33:398-406.

125. Nikkhah D, Booth S, Tay S, et al. Comparing outcomes of sheet grafting with 1:1 mesh grafting in patients with thermal burns: a randomized trial. Burns 2015;41:257-64.

126. Noorbala MT, Noorbala M, Dashti-Rahmatabadi $\mathrm{MH}$, et al. Comparison of hydrogel produced by radiation as applied at the research center (yazd branch) with maxgel and routine dressing for second-degree Burn Repair in Yazd Burn Hospital. Iran Red Crescent Med J 2016;18

127. Oen IM, van Baar ME, Middelkoop E, et al. Effectiveness of cerium nitrate-silver sulfadiazine in the treatment of facial burns: multicenter, randomized, controlled trial. Plastic and reconstructive surgery 2012;130:274e-83.

128. Omar MTA, Hegazy FA, Mokashi SP. Influences of purposeful activity versus rote exercise on improving pain and hand function in pediatric burn. Burns 2012;38:261-8.

129. Orrey DC, Halawa OI, Bortsov AV, et al. Results of a pilo multicenter genotype-based randomized placebo-controlled trial of propranolol to reduce pain after major thermal burn injury. Clin $J$ Pain 2015;31:21-9.

130. Omranifard M, Heidari M, Farajzadegan Z, et al. Botulinum toxin and burn induces contracture. Arch Plast Surg 2016;43:609-11.

131. Ostadrahimi A, Nagili B, Asghari-Jafarabadi M, et al. A proper enteral nutrition support improves sequential organ failure score and decreases length of stay in hospital in burned patients. Iran Red Crescent Med J 2016;18.

132. Ostlie DJ, Juang D, Aguayo P, et al. Topical silver sulfadiazine vs collagenase ointment for the treatment of partial thickness burns in children: a prospective randomized trial. J Pediatr Surg 2012;47:1204-7.

133. Ottomann C, Stojadinovic A, Lavin PT, et al. Prospective randomized phase II trial of accelerated reepithelialization of superficial second-degree burn wounds using extracorporeal shock wave therapy. Ann Surg 2012;255:23-9.

134. Ouyang J, Chen Y-chuan, Luo G-xing, Y-c C, G-x L, et al. A randomized and controlled multicenter prospective study of the chinese medicinal compound fufang xuelian burn ointment for the treatment of superficial and deep second-degree burn wounds. Cell Biochem Biophys 2014;69:467-74

135. Palmieri TL, Greenhalgh DG, Sen S. Prospective comparison of packed red blood cell-to-fresh frozen plasma transfusion ratio of 4 : 1 versus 1: 1 during acute massive burn excision. Journal of Trauma and Acute Care Surgery 2013;74:76-83.

136. Panahi $\mathrm{Y}$, Beiraghdar $\mathrm{F}$, Akbari $\mathrm{H}$, et al. A herbal cream consisting of Aloe vera, Lavandula stoechas, and Pelargonium roseum as an alternative for silver sulfadiazine in burn management. Asian Biomedicine 2012;6:273-8.

137. Parker M, Delahunty B, Heberlein N, et al. Interactive gaming consoles reduced pain during acute minor burn rehabilitation: $A$ randomized, pilot trial. Burns 2016;42:91-6.

138. Parry I, Painting L, Bagley A, et al. A pilot prospective randomized control trial comparing exercises using videogame therapy to standard physical therapy: 6 months follow-up. J Burn Care Res 2015;36:534-44.

139. Patton ML, Mullins RF, Smith D, et al. An open, prospective, randomized pilot investigation evaluating pain with the use of a soft silicone wound contact layer vs bridal veil and staples on split thickness skin grafts as a primary dressing. J Burn Care Res 2013;34:674-81.

140. Peña R, Ramirez LL, Crandall CG, et al. Effects of communitybased exercise in children with severe burns: A randomized trial. Burns 2016;42:41-7.

141. Porro LJ, Al-Mousawi AM, Williams F, et al. Effects of propranolol and exercise training in children with severe burns. $J$ Pediatr 2013;162:799-803.

142. Porro LJ, Herndon DN, Rodriguez NA, et al. Five-year outcomes after oxandrolone administration in severely burned children: a randomized clinical trial of safety and efficacy. J Am Coll Surg 2012;214:489-502

143. Portilla AS, Bravo GL, Miraval FK, et al. A feasibility study assessing cortical plasticity in chronic neuropathic pain following burn injury. Burn Care Res 2013;34:e48-e52.

144. Rashaan ZM, Krijnen P, van den Akker- van Marle ME, et al. Clinical effectiveness, quality of life and cost-effectiveness of Flaminal ${ }^{\circledR}$ versus Flamazine $₫$ in the treatment of partial thickness burns: study protocol for a randomized controlled trial. Trials 2016;17:122.

145. Reeves PT, Herndon DN, Tanksley JD, et al. Five-year outcomes after long-term oxandrolone administration in severely burned children: a randomized clinical trial. Shock 2016;45:367-74.

146. Rosenberg L, Krieger Y, Bogdanov-Berezovski A, et al. A novel rapid and selective enzymatic debridement agent for burn wound management: a multi-center RCT. Burns 2014;40:466-74.

147. Rousseau A-F, Foidart-Desalle M, Ledoux D, et al. Effects of cholecalciferol supplementation and optimized calcium intakes on vitamin D status, muscle strength and bone health: A one-year pilot randomized controlled trial in adults with severe burns. Burns 2015;41:317-25.

148. Salehi SH, As'adi K, Mousavi SJ, et al. Evaluation of amniotic membrane effectiveness in skin graft donor site dressing in burn patients. Indian J Surg 2015;77:427-31.

149. Schaden E, Kimberger O, Kraincuk P, et al. Perioperative treatment algorithm for bleeding burn patients reduces allogeneic blood product requirements. Br J Anaesth 2012;109:376-81.

150. Schulz A, Depner $C$, Lefering $R$, et al. A prospective clinical tria comparing Biobrane $(\circledR)$ Dressilk $(\circledR)$ and PolyMem $(\circledR)$ dressings on partial-thickness skin graft donor sites. Burns 2016;42:345-55.

151. Shahzad MN, Ahmed N. Effectiveness of Aloe vera gel compared with $1 \%$ silver sulphadiazine cream as burn wound dressing in second degree burns. J Pak Med Assoc 2013;63:225-30.

152. Siadat $A H$, Iraji $F$, Bahrami $R$, et al. The comparison between modified kligman formulation versus kligman formulation and intense pulsed light in the treatment of the post-burn hyperpigmentation. Adv Biomed Res 2016;5.

153. Soltan Dallal MM, Safdari R, Emadi Koochak H, et al. A comparison between occlusive and exposure dressing in the management of burn wound. Burns 2016;42:578-82.

154. Sood R, Roggy DE, Zieger MJ, et al. A comparative study of spray keratinocytes and autologous meshed split-thickness skin graft in the treatment of acute burn injuries. Wounds 2015;27:31-40.

155. Sousse LE, Herndon DN, Mlcak RP, et al. Long-term administration of oxandrolone improves lung function in pediatric burned patients. J Burn Care Res 2016;37:273-7.

156. Tang H, Lv G, Fu J, et al. An open, parallel, randomized, comparative, multicenter investigation evaluating the efficacy and tolerability of Mepilex Ag versus silver sulfadiazine in the treatment of deep partial-thickness burn injuries. J Trauma Acute Care Surg 2015;78:1000-7.

157. Taudorf EH, Danielsen PL, Paulsen IF, et al. Non-ablative fractional laser provides long-term improvement of mature burn scars--a randomized controlled trial with histological assessment. Lasers Surg Med 2015;47:141-7.

158. Tokarik M, Sjöberg F, Balik M, et al. Fluid Therapy LiDCO Controlled Trial-optimization of volume resuscitation of extensively burned patients through noninvasive continuous real-time hemodynamic monitoring LiDCO. Journal of Burn Care \& Research 2013;34:537-42.

159. Vejdan SA, Khosravi M, Zojaji F. Burn donor site dressing using melolin and flexigrid versus conventional dressing. Shiraz $E$ Med J $2015 ; 16$.

160. Venclauskiene A, Basevicius A, Zacharevskij E, et al. Laser Doppler imaging as a tool in the burn wound treatment protocol. Videosurgery and Other Miniinvasive Techniques 2014;1:24-30.

161. Venet F, Plassais J, Textoris J, et al. Low-dose hydrocortisone reduces norepinephrine duration in severe burn patients: a randomized clinical trial. Critical Care 2015;19:21.

162. Venkatachalapathy TS. A comparative study of paediatric thermal burns treated with topical heparin and without heparin. Indian $J$ Surg 2014;76:282-7.

163. Verhaegen PD, Bloemen MC, van der Wal MB, et al. Skin stretching for primary closure of acute burn wounds. Burns 2014;40:1727-37.

164. Voon K, Silberstein I, Eranki A, et al. Xbox Kinect ${ }^{\mathrm{TM}}$ based rehabilitation as a feasible adjunct for minor upper limb burns rehabilitation: A pilot RCT. Burns 2016;42:1797-804.

165. Wang C, Wang J, Feng J. Local application of low-dose insulin in improving wound healing after deep burn surgery. Exp Ther Med 2016;12:2527-30.

166. Wibbenmeyer L, Eid A, Liao J, et al. Gabapentin is ineffective as an analgesic adjunct in the immediate postburn period. J Burn Care Res 2014;35:136-42.

167. Wood F, Martin L, Lewis D, et al. A prospective randomised clinical

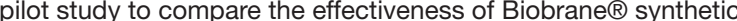
wound dressing, with or without autologous cell suspension, to the local standard treatment regimen in paediatric scald injuries. Burns 2012:38:830-9. 
168. Wu J, Xu R, Zhan R, et al. Effective symptomatic treatment for severe and intractable pruritus associated with severe burn-induced hypertrophic scars: a prospective, multicenter, controlled trial. Burns 2016;42:1059-66.

169. Wurzer P, Branski LK, Clayton RP, et al. Propranolol reduces cardiac index but does not adversely affect peripheral perfusion in severely burned children. Shock 2016;46:486-91.

170. Xiao H, Li C, Zhou X, et al. A new method of microskin autografting with a Vaseline-based moisture dressing on granulation tissue. Burns 2014;40:337-46.

171. Yan $\mathrm{H}$, Chen J, Peng X. Recombinant human granulocytemacrophage colony-stimulating factor hydrogel promotes healing of deep partial thickness burn wounds. Burns 2012;38:877-81.

172. Yarboro DD. A comparative study of the dressings silver sulfadiazine and Aquacel Ag in the management of superficial partial-thickness burns. Adv Skin Wound Care 2013;26:259-62.

173. Yim H, Yang HT, Cho YS, et al. A clinical trial designed to evaluate the safety and effectiveness of a thermosensitive hydrogel-type cultured epidermal allograft for deep second-degree burns. Burns 2014;40:1642-9.

174. Yuan L, Minghua C, Feifei D, et al. Study of the use of recombinant human granulocyte-macrophage colony-stimulating factor hydroge externally to treat residual wounds of extensive deep partialthickness burn. Burns 2015;41:1086-91.

175. Zahmatkesh M, Manesh MJ, Babashahabi R. Effect of olea ointment and acetate mafenide on burn wounds - a randomized clinical trial. Iran J Nurs Midwifery Res 2015;20:599.

176. Zhang J, Li X, Gao Y, et al. Effects of puerarin on the inflammatory role of burn-related procedural pain mediated by $\mathrm{P} 2 \mathrm{X}(7)$ receptors. Burns 2013;39:610-8.

177. Zidan SM, Eleowa SA, Nasef MA, et al. Maximizing the safety of glycerol preserved human amniotic membrane as a biological dressing. Burns 2015;41:1498-503.

178. Zu H, Li Q, Huang P, et al. Therapeutic value of blood purification and prognostic utilities of early serum procalcitonin, C Reactive Protein, and Brain Natriuretic Peptide Levels in Severely Burned Patients with Sepsis. Cell Biochem Biophys 2015;72:259-63.

179. Wasiak J, Cleland H, Campbell F. Dressings for superficial and partial thickness burns. Cochrane Database Syst Rev 2008;4.

180. Clare G, Suleman $\mathrm{H}$, Bunce $\mathrm{C}$, et al. Amniotic membrane transplantation for acute ocular burns. Cochrane Database Syst Rev 2011;9.

181. Breederveld RS, Tuinebreijer WE. Recombinant human growth hormone for treating burns and donor sites. Cochrane Database Syst Rev 2014:104:CD008990.

182. Dumville JC, Munson C. Negative pressure wound therapy for partial-thickness burns. Cochrane Database Syst Rev 2012;12:CD006215.

183. Barajas-Nava LA, López-Alcalde J, Roqué i Figuls M, et al. Antibiotic prophylaxis for preventing burn wound infection. Cochrane Database Syst Rev 2013;6:CD008738.

184. Hoogewerf CJ, Van Baar ME, Hop MJ, et al. Topical treatment for facial burns. Cochrane Database Syst Rev 2013;29:CD008058.

185. Wasiak J, Mahar PD, McGuinness SK, et al. Intravenous lidocaine for the treatment of background or procedural burn pain. Cochrane Database Syst Rev 2014;37.

186. Tan HB, Danilla S, Murray A, et al. Immunonutrition as an adjuvant therapy for burns. Cochrane Database Syst Rev 2014;18.

187. Masters B, Aarabi S, Sidhwa F, et al. High-carbohydrate, high-protein, low-fat versus low-carbohydrate, high-protein, high-fat enteral feeds for burns. Cochrane Database Syst Rev 2012;1:CD006122.

188. Potter S, Brigic A, Whiting PF, et al. Reporting clinical outcomes of breast reconstruction: a systematic review. J Natl Cancer Inst 2011:103:31-46.
189. Blencowe NS, Strong S, McNair AGK, et al. Reporting of short-term clinical outcomes after esophagectomy. Ann Surg 2012;255:658-66.

190. Whitehead L, Perkins GD, Clarey A, et al. A systematic review of the outcomes reported in cardiac arrest clinical trials: the need for a core outcome set. Resuscitation 2015;88:150-7.

191. Hayes J, Black N, Jenkinson C, et al. Outcome measures for adult critical care: a systematic review. Health technology assessment 2000;4:1-111.

192. Zakrzewska JM, Lopez BC. Quality of reporting in evaluations of surgical treatment of trigeminal neuralgia: recommendations for future reports. Neurosurgery 2003;53:110-22.

193. Riddle DL, Stratford PW, Bowman DH. Findings of extensive variation in the types of outcome measures used in hip and knee replacement clinical trials: a systematic review. Arthritis Rheum 2008;59:876-83.

194. McNaughton-Collins M. Health-related quality of life, satisfaction, and economic outcome measures in studies of prostate cancer screening and treatment, 1990-2000. J Nat/ Cancer Inst Monogr 2004;2004:78-101.

195. Deyo RA, Battie M, Beurskens AJ, et al. Outcome measures for low back pain research. a proposal for standardized use. Spine 1998;23:2003-13.

196. Bruce J, Russell EM, Mollison J, et al. The quality of measurement of surgical wound infection as the basis for monitoring: a systematic review. J Hosp Infect 2001;49:99-108.

197. Bruce J, Krukowski ZH, Al-Khairy G, et al. Systematic review of the definition and measurement of anastomotic leak after gastrointestinal surgery. Br J Surg 2001;88:1157-68.

198. Dodd S, Clarke M, Becker L, et al. A taxonomy has been developed for outcomes in medical research to help improve knowledge discovery. J Clin Epidemiol 2018;96:84-92.

199. Boers M, Kirwan JR, Wells G, et al. Developing core outcome measurement sets for clinical trials: OMERACT filter 2.0. J Clin Epidemiol 2014;67:745-53.

200. Clarke M. Standardising outcomes for clinical trials and systematic reviews. Trials 2007:8:39.

201. Clarke M. Standardising Outcomes in Paediatric Clinical Trials. PLoS Med 2008;5:e102.

202. Kirkham JJ, Boers M, Tugwell P, et al. Outcome measures in rheumatoid arthritis randomised trials over the last 50 years. Trials 2013;14:324.

203. Bautista-Molano W, Navarro-Compán V, Landewé RB, et al. How well are the ASAS/OMERACT Core Outcome Sets for Ankylosing Spondylitis implemented in randomized clinical trials? A systematic literature review. Clin Rheumatol 2014;33:1313-22.

204. Falder S, Browne A, Edgar D, et al. Core outcomes for adult burn survivors: a clinical overview. Burns 2009;35:618-41.

205. Kirkham JJ, Davis K, Altman DG, et al. Core Outcome SetSTAndards for Development: The COS-STAD recommendations. PLOS Med 2017:14:e1002447.

206. Kirkham JJ, Gorst S, Altman DG, et al. Core outcome SetSTAndards for reporting: The COS-STAR statement. PLoS Med 2016;13:e1002148

207. (COMET) COMiET.

208. Gargon E, Williamson PR, Altman DG, et al. The COMET Initiative database: progress and activities from 2011 to 2013. Trials 2014;15:279.

209. Chiarotto A, Ostelo RW, Turk DC, et al. Core outcome sets for research and clinical practice. Braz J Phys Ther 2017;21:77-84.

210. Gorst SL, Gargon E, Clarke M, et al. Choosing important health outcomes for comparative effectiveness research: an updated review and user survey. PLoS One 2016;11:e0146444.

211. Biggane AM, Brading L, Ravaud P, et al. Survey indicated that core outcome set development is increasingly including patients, being conducted internationally and using Delphi surveys. Trials 2018;19:113. 